\title{
Gestão ambiental no setor de alimentação coletiva: estratégias de educação ambiental e marketing verde
}

As empresas passam por um período de transição e implementação de ações sustentáveis e estão sendo desafiadas a encontrar novas formas e práticas produtivas sustentáveis. Para isso, e preciso entender o conhecimento ambiental dos colaboradores e clientes. Objetivou-se, nesse estudo, realizar um diagnóstico do impacto ambiental e da percepção socioambiental em um restaurante-escola, visando desenvolver ações de práticas sustentáveis baseadas em ferramentas de educação ambiental e marketing verde. Aplicou-se uma pesquisa caraterística mista quali-quantitativa, com pesquisa de campo realizado por meio de observações sistemáticas dos processos de produção e de gerenciamento do estabelecimento, e aplicação dos instrumentos de pesquisa (questionários e matriz de impacto ambiental). Foi aplicado, com os 13 colaboradores, um instrumento composto por quatro blocos de questionários de percepção nas seguintes de pesquisa (questionários e matriz de impacto ambiental). Foi aplicado, com os 13 colaboradores, um instrumento composto por quatro blocos de questionários de percepção nas seguintes ecológico onde se analisaram os resultados, com o intuito de caracterizar os indivíduos avaliando os fatores: preocupação global e local; consumo verde; atitude local; decrescimento; antropocentrismo; crenças; controle do crescimento Econômico. Após a aplicação dos instrumentos de diagnóstico, apresentou-se a proposta de gestão ambiental. A partir da análise de percepção, constatou-se que os envolvidos possuem uma preocupação ambiental, mas o consumo verde ainda não se realiza e as ferramentas de gestão socioambientais vêm para contribuir com essa mudança transmitindo valores ecológicos e adotando práticas e ações sustentáveis para que possa se tronar uma empresa verde.

Palavras-chave: Ferramentas de Gestão Socioambiental; Marketing Ambiental; Restaurante Escola; Sensibilização Ambiental; Sustentabilidade.

\section{Environmental management in the collective food sector: environmental education strategies and green marketing}

\begin{abstract}
Companies are going through a period of transition and implementation of sustainable actions and are being challenged to find new ways and sustainable production practices. This requires understanding the environmental knowledge of employees and customers. The objective of this study was to make a diagnosis of environmental impact and social and environmenta perception in a school restaurant, aiming to develop actions of sustainable practices based on environmental education tools and green marketing. A qualitative and quantitative mixed characteristic research was appied, with field research conduted throu systematic obsevations of the establishment's production and manaeme processes, and application of the char the following themes: ecological behavior; social behavior; individualism and collectivism; and socio-environmental knowledge. For the 300 clients, the scale of the new ecological paradigm was adopted, where the results were analyzed, in order to characterize the individuals evaluating the factors: global and local concern; green consumption; local attitude; degrowth; anthropocentrism; beliefs; control of economic growth. After the application of the diagnostic instruments, the environmental management proposal was presented. From the analysis of perception, it was found that those involved have an environmental concern, but green consumption is not yet realized and social and environmental management tools come to contribute to this change by transmitting ecological values and adopting sustainable practices and actions so that it can become a green company.
\end{abstract}

Keywords: Social and Environmental Management Tools; Environmental marketing; School Restaurant; Environmental awareness; Sustainability.

Topic: Sistemas de Gestão Ambiental

Reviewed anonymously in the process of blind peer.
Received: 22/10/2018

Approved: 23/11/2018
Pamella Olivia Felisberto (D)

Centro Universitário Cesumar, Brasil

http://lattes.cnpq.br/8656747201313407

http://orcid.org/0000-0002-2818-8290

pamfelisberto@gmail.com

\section{Queila Turchetto (iD)}

Centro Universitário Cesumar, Brasil

http://lattes.cnpq.br/3571683471770302

http://orcid.org/0000-0003-2626-1033

queilat@gmail.com

Cleiltan Novais da Silva

Centro Universitário Cesumar, Brasil

http://lattes.cnpq.br/9993910421974160

cleiltan@gmail.com

\author{
Rute Grossi Milani (iD) \\ Centro Universitário Cesumar, Brasil \\ http://lattes.cnpq.br/8844448878404124 \\ http://orcid.org/0000-0003-2918-1266 \\ rute.milani@unicesumar.edu.br \\ Rejane Sartori (iD \\ Centro Universitário Cesumar, Brasil \\ http://lattes.cnpq.br/2212790934134878 \\ http://orcid.org/0000-0001-9116-5860 \\ rejanestr@gmail.com \\ Isabele Picada Emanuelli (iD \\ Centro Universitário Cesumar, Brasil \\ http://lattes.cnpq.br/7211889533862650 \\ http://orcid.org/0000-0002-1423-2748 \\ isabelevet@hotmail.com
}

Referencing this:

FELISBERTO, P. O.; TURCHETTO, Q.; SILVA, C. N.; MILANI, R. G.; SARTORI, R.; EMANUELLI, I. P.. Gestão ambiental no setor de alimentação coletiva: estratégias de educação ambiental e marketing verde. Revista Ibero-Americana de Ciências Ambientais, v.9, n.8, p.319-342, 2018. DOI: http://doi.org/10.6008/CBPC21796858.2018.008.0028

DOI: 10.6008/CBPC2179-6858.2018.008.0028 


\section{INTRODUÇÃO}

A forma de produção vigente e o estilo de vida baseado em produtos industrializados têm causado danos preocupantes ao meio ambiente colocando em risco a sobrevivência das futuras gerações (AXON, 2017). A inserção da sustentabilidade nos modelos produtivos e de consumo é fator preponderante para o equilíbrio ambiental, sendo um desafio para os setores organizacionais, principalmente para o aprimoramento dos modelos produtivos na busca de empresas ambientalmente corretas (TSENG et al., 2018). Este desafio foi contemplado na agenda 2030 da ONU (2015), onde o objetivo 12, dos 17 objetivos para o desenvolvimento sustentável (ODS), visa assegurar os padrões de produção e de consumo sustentáveis (ONU, 2015).

Essa preocupação mundial começou a refletir diretamente nos ambientes organizacionais de produção e de serviços, direcionando-os à sustentabilidade nos aspectos social, econômico e ambiental visando assegurar o bem-estar das gerações presentes e futuras a partir do uso racional e consciente dos recursos disponíveis (FLEMING et al., 2017; THONGPLEW et al., 2017). Dessa maneira, as organizações exercem um papel importante nas práticas de desenvolvimento produtivo e de valores sustentáveis, todavia nos segmentos do mercado alimentício, essa temática ainda é pouco expressiva (FLEMING et al., 2017).

O setor de restaurantes, ainda é visto como um dos setores econômicos menos sustentáveis do mundo (PUNTEL et al., 2015). No entanto, observa-se uma atenção especial com as questões ambientais e sociais, evidenciada, por exemplo, pelo crescimento e desenvolvimento de restaurantes designados verdes (KWOK et al., 2016; WANG, 2016) bem como pela preocupação em minimizar o uso de recursos e de gerar menos resíduos (HU et al., 2010).

No ano de 2016, o Brasil movimentou neste setor uma economia de $\mathrm{R} \$ 184 \mathrm{bi}$ com aproximadamente 14 bilhões de pessoas alimentando-se fora de casa com frequência (AMARAL, 2017). Por conseguinte, junto com este crescimento, crescem os problemas ambientais ocasionados pelo consumo excessivo de energia, água, pela geração de grandes quantidades de resíduos não recicláveis e pelo desperdício de alimentos (HU et al., 2013).

Juntamente com a problemática ambiental, cresce a necessidade de as empresas adotarem práticas empresariais de sustentabilidade para obterem vantagens competitivas e, ao mesmo tempo, não comprometer aspectos de sustentabilidade é o mais almejado no mercado atual (SMITH et al., 2012). Diante disso, as empresas estão introduzindo ferramentas de gerenciamento ambiental ao seu modelo de gestão, visando assim diminuir o impacto ambiental, aumentar a competitividade no mercado e até mesmo reduzir os custos (ALVES et al., 2013).

$\mathrm{Na}$ literatura científica encontramos diversos tipos de ferramentas que podem ser utilizadas em restaurantes, algumas mais frequentes como práticas de produção mais limpa (SEVERO et al., 2014; SILVESTRE et al., 2014), as certificações (BARBIERI et al., 2009), as pegadas ecológicas (SATO et al., 2010), hídricas de carbono (LAMIM-GUEDES, 2013); estratégias de marketing verde (DAHLSTROM, 2011). Todavia, para que essas práticas de gerenciamento socioambiental alcancem este diferencial é fundamental 
apresentar a Educação Ambiental como um instrumento fundamental de gestão, sendo abordado e executado por meio de mudanças de valores, conceitos e comportamentos (ALCÂNTARA et al., 2012).

É importante destacar que, para a implementação de um modelo de gestão ambiental eficiente, não basta apenas mudanças nos sistemas de produção; deve-se entender a forma de pensar dos atores envolvidos, ou seja, na percepção humana das pessoas inseridas no meio. Nesse sentido, são necessários estudos com uma visão holística para a resolução do problema da sustentabilidade do setor de alimentação coletiva, aliando os fundamentos gerenciais, socioambientais e educacionais. Dessa maneira, o objetivo deste trabalho foi realizar um estudo de caso em um restaurante, avaliando o impacto ambiental e a percepção socioambiental para propor ações de gestão sustentável, com ênfase em ferramentas de educação ambiental e marketing verde.

\section{METODOLOGIA}

A base metodológica da pesquisa teve caraterística mista quali-quantitativa (KIRSCHBAUM, 2013) mediante associação dos procedimentos de estudo de caso com pesquisa de campo. 0 estudo de caso foi realizado por meio de observações sistemáticas dos processos de produção e de gerenciamento do estabelecimento, e a pesquisa de campo foi desenvolvida mediante levantamento de dados e aplicação dos instrumentos de pesquisa (questionários e matriz de impacto ambiental).

Para tanto, a metodologia do trabalho foi estruturada em três etapas: caracterização do local de estudo; análise da percepção socioambiental; e a última seção apresenta a caracterização da proposta de gestão ambiental. Para garantir a integridade ética do instrumento, a pesquisa foi registrada na Plataforma Brasil, submetida ao Comitê de Ética em Pesquisa envolvendo Seres Humanos (CEP) sob o parecer nำ2.505.222 e aprovada conforme resolução no 466/2002.

\section{Caracterização do local de estudo}

O estudo de caso foi desenvolvido em um Restaurante Escola (RE), localizado na região Noroeste do Paraná na cidade de Maringá (Latitude: $23^{\circ} 25^{\prime} 31^{\prime \prime}$ S; Longitude: 51 $56^{\prime} 19^{\prime \prime}$ O). O RE, objeto do estudo, está alocado dentro de uma Instituição de Ensino Superior (IES) privada atendendo os seguintes públicos: 11.000 alunos no curso presencial, 2.500 professores e colaboradores, 1.000 alunos do colégio junto a instituição, 3.500 alunos no polo de educação a distância, 2.800 em pós-graduação e flutuante nas clínicas na instituição 5.000 pessoas. 0 estabelecimento funciona de segunda a sábado servindo, aproximadamente, 250 refeições diárias e é considerado uma pequena empresa.

É um ambiente destinado tanto para produção, comercialização como para o consumo de alimentos. Para caracterização do restaurante foi realizada uma entrevista com o gestor, levantamento de dados da produção e consumo e quantificado os atendimentos, a geração de resíduos, a destinação e os possíveis tratamentos final dos mesmos, apresentados pela empresa. 


\section{Diagnóstico do impacto ambiental}

Para a mensuração do impacto ambiental do estabelecimento, foi utilizada uma adaptação da matriz de impactos ambiental propostas por Leopold et al. (1971). Na fase inicial da matriz, foram identificados e enumerados os possíveis impactos ambientais e os fenômenos que ocasionam. Os fenômenos ambientais analisados na matriz foram: Preparo de alimentos e sucos a base de laranja; Preparo de alimentos na cozinha utilizando o método de fritura; Recebimento e estocagem de alimentos embalados; Serviço de alimentação por buffet; Serviço de alimentação a la carte; Materiais recicláveis de consumo e higiene descartados pelos clientes. Em seguida, atribuiu-se as respectivas composições da magnitude para cada fenômeno. A composição da magnitude é a soma dos valores determinados para os sentidos, forma de incidência, distributividade, tempo de incidência, prazo de permanência.

A soma destes valores resulta no valor de magnitude para cada tipo de fenômeno, variando de -8 a 8, onde -8 é o máximo de impacto causado. Em seguida, os dados quantitativos deste valor de magnitude, resultam nos atributos dos impactos ambientais (magnitude, intensidade, importância), para enfim, originar o Valor de Relevância Global do impacto (VRG), que representa o valor final do impacto. Este valor pode variar de -125 a +125 , tendo como o ideal, valores próximos a zero. O impacto foi qualificado em alto, médio e baixo (figura 1).

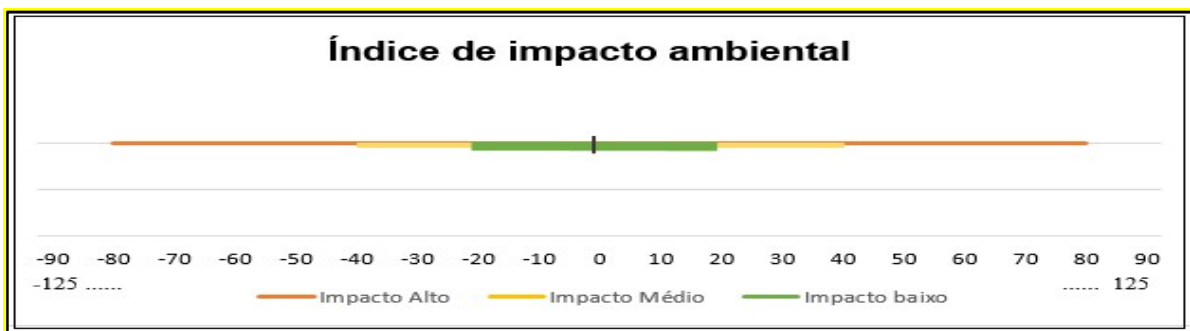

Figura 1: Variação de impacto ambiental fornecida pela MIA. O valor VRG pode variar de -125 a +125 , tendo como o ideal, valores próximos a zero. 0 impacto foi qualificado em alto (-125 a -40; e +40 a +125), médio (-40 a -20; e +20 a $+40)$ e baixo $(-20 \mathrm{a}+20)$.

\section{Diagnóstico da percepção socioambiental}

A percepção socioambiental foi avaliada pela aplicados dois Instrumentos: o questionário ' $A$ ' para os colaboradores e o questionário ' $B$ ' para os clientes. O questionário ' $A$ ' é uma análise mais complexa e extensa, ao contrário do 'B' que era sucinto, descritos a seguir. Para analisar a percepção socioambiental dos colaboradores do RE, foi aplicado o questionário A formado por quatro blocos temáticos.

O questionário é semiestruturado e foi aplicado aos 13 colaboradores dos diferentes setores, com idade entre 20 a 49 anos, sendo 4 do sexo masculino e 9 do sexo feminino. As questões do questionário $A$ visaram identificar o conhecimento e o comportamento pró-social e pró-ambiental. Os quatro blocos do questionário de percepção basearam-se nas seguintes temáticas já propostas na literatura: comportamento de uso da água e percepção sobre o consumo (desperdício) de escala de Individualismo e Coletivismo (GOUVEIA, 1998); as subescalas de presente e de futuro do Inventário Zimbardo de Perspectiva Temporal (ZIMBARDO et al., 1999); a Escala Novo Paradigma Ecológico (DUNLAP et al., 2000). 
Além disso, incluía a caracterização sócio demográfica (sexo, idade, origem). As temáticas do questionário foram distribuídas em quatro blocos avaliativos: comportamento ecológico; comportamento social; Individualismo e Coletivismo, e conhecimento socioambiental. Todos os blocos continham perguntas de múltipla escolha na escala tipo Likert variando os níveis conforme a literatura (PATO et al., 2006; PATO, 2004; QUEVEDO, 2005). A análise estatística dos dados foi realizada de acordo com Pato et al. (2006).

Quando nenhum teste era adequado, foi realizada uma análise descritiva dos dados. Foi realizada uma análise descritiva dos resultados para a obtenção de gráficos e tabelas de frequência, com o intuito de caracterizar os indivíduos. Para descrição dos resultados foram utilizadas a frequência absoluta e a porcentagem para as variáveis categóricas. A frequência absoluta ( $\mathrm{n}$ i $\mathrm{i}$ é dada pelo número de vezes em que uma determinada variável assume um determinado valor/categoria em questão. A porcentagem (p_i) é o resultado da razão entre a frequência absoluta e o tamanho da amostra, multiplicado por 100, isto é, 100.n_i/n\%. Todas as análises foram realizadas com o auxílio do ambiente estatístico R ( $R$ Development Core Team), versão 3.3.1, e o nível de significância foi fixado em 5\%.

Para analisar a percepção socioambiental dos clientes do RE foi aplicado outro questionário, chamado de questionário B. O objetivo deste questionário foi identificar o conhecimento e o comportamento pró-social e pró-ambiental. Para tanto, adotou-se a escala do novo paradigma ecológico (Escala-NEP), desenvolvida por Dunlap et al. (1978) e atualizada por Dunlap et al. (2000). Foi realizada uma análise descritiva dos resultados para a obtenção de gráficos e tabelas de frequência, com o intuito de caracterizar os indivíduos.

A aplicação do questionário foi realizada em 300 clientes escolhidos aleatoriamente. Inicialmente, o questionário aborda itens gerais de caracterização sociodemográfica (gênero, idade, estado civil), além do tipo de vínculo dos entrevistados com a IES (estudante da IES, colaborador da IES ou cliente externo). Este questionário é composto por apenas um bloco com 26 questões semiestruturadas que avaliam sete fatores: preocupação global e local (PRGL); consumo Verde (CV); Atitude Local (AL); decrescimento (DC); antropocentrismo (AT); crenças (CR); Controle do Crescimento Econômico.

Cada questão possuía cinco alternativas de respostas, que quantificam a concordância com a mesma, onde 1 é designado para a resposta 'discordo totalmente'; 2 para 'discordo em parte'; 3 para 'não concordo nem discordo'; 4 para 'concordo em parte' e 5 para 'concordo totalmente'. Sendo assim, a pontuação de cada fator varia entre 1 a 5 pontos, e quanto maior o valor, maior é a concordância com as questões que o compõem. Para o tratamento estatístico utilizou-se inicialmente uma análise descritiva dos dados.

Em seguida, verificou-se o valor alfa de Cronbach para as 26 questões (anexo III) e obteve-se o valor de 0,790, considerado bom (Field, 2013). Em seguida, foi realizada a análise fatorial sobre as questões 1 a 26 de cada um dos questionários. Todas as análises foram realizadas com o auxílio do ambiente estatístico $R$ ( $R$ Development Core Team), versão 3.3.1, e o nível de significância em 5\%. 


\section{Pontos de intervenção da sensibilização ambiental}

A proposta de gestão foi efetuada após a caracterização do estabelecimento, entrevista com o gestor, o diagnóstico do impacto ambiental e o diagnóstico da percepção socioambiental dos envolvidos no processo, tanto cliente quanto colaboradores. Nesta etapa foram apresentadas as propostas de gerenciamento socioambiental e as ferramentas de gestão ambiental que serão aplicadas nos pontos de intervenção detalhada. O processo gerencial sustentável foi desenvolvido em quatro etapas: gestão ambiental; sensibilização ambiental; educação ambiental; e marketing verde; englobando todos os envolvidos, no Restaurante Escola, como: gerência, chefe de cozinha, colaboradores e clientes.

Para completar o processo gerencial mapearam-se os pontos de intervenção para a aplicação das ferramentas de gestão ambiental. Os pontos de intervenções foram detectados pelo diagnóstico do processo produtivo e pelo diagnóstico da percepção ambiental dos colaboradores e clientes, relacionadas ao processo de produtivo (produção/armazenamento embalagem, nas dimensões gerência, chefe de cozinha, colaboradores; escolha do cardápio nas dimensões gerência, chefe de cozinha); e as relacionadas ao consumo e o descarte (Consumo, Desperdício; Embalagens e Materiais Descartáveis Descarte, ambas nas dimensões gerência, chefe de cozinha, colaboradores e clientes).

\section{RESULTADOS E DISCUSSÃO}

O estudo de caso do RE foi realizado pela análise dos diagnósticos de impacto ambiental do estabelecimento e de percepção socioambiental dos colaboradores e clientes. Posteriormente, foram desenvolvidas as propostas de práticas de gestão sustentáveis baseadas em estratégias de educação ambiental e marketing verde.

\section{Diagnóstico do impacto ambiental}

Os dados da gerência do RE indicaram uma média de 2700 atendimentos por semana (6 dias), sendo café da manhã, almoço, lanche e jantar; exceto aos sábados que atende apenas até o horário de almoço. A média de resíduos sólidos gerados no RE foi de 101,55kg por dia, sendo a produção de resíduo per capita de aproximadamente $0,23 \mathrm{~kg} /$ comensal/dia.

Como o restaurante não utilizava nenhum tipo de gerenciamento e monitoramento ambiental dos processos produtivos aplicou-se a MIA com os fenômenos ambientais mais relevantes (tabela 1). A MIA indicou um índice de impacto -86 a 4, com uma média de -33, sendo classificado como médio (figura 1), confirmando a hipótese da necessidade de aplicação de instrumentos que mensurasse a percepção socioambiental nos indivíduos envolvidos tanto no processo produtivo (colaboradores), como no processo de consumo (clientes). Sendo assim, a próxima seção apresenta a percepção socioambiental dos colaboradores e clientes. 
Tabela 1: Fenômenos ambientais encontrados no restaurante escola e suas atribuições em graus de magnitude, intensidade e importância e o valor de relevância global (VRG) dos impactos.

\begin{tabular}{|c|c|c|c|c|}
\hline \multirow[b]{2}{*}{ Fenômenos Ambientais } & \multicolumn{4}{|c|}{ ATRIBUTOS DOS IMPACTOS AMBIENTAIS } \\
\hline & $\begin{array}{l}\text { Magnitude (1 } \\
\text { a 5) }\end{array}$ & $\begin{array}{l}\text { Intensidade (1 } \\
\text { a 5) }\end{array}$ & $\begin{array}{l}\text { Importância (1 } \\
\text { a 5) }\end{array}$ & $\begin{array}{l}\text { VRG* (1 a } \\
125)\end{array}$ \\
\hline $\begin{array}{l}\text { 1- Preparo de alimentos e sucos de laranja: Geração de Resíduos orgânicos do } \\
\text { subproduto; }\end{array}$ & 2 & 1 & 2 & 4 \\
\hline $\begin{array}{l}\text { 2- Preparo de alimentos na cozinha utilizando o método de fritura: venda } \\
\text { correta do óleo descarte; }\end{array}$ & -3 & 5 & 5 & -75 \\
\hline $\begin{array}{l}\text { 3- Recebimento e estocagem de alimentos embalados: descarte das embalagens } \\
\text { recicláveis sem separação; }\end{array}$ & -4 & 4 & 5 & -80 \\
\hline $\begin{array}{l}\text { 4- Serviço de alimentação por buffet prestado pelo restaurante: Geração de } \\
\text { Resíduos orgânicos sobra buffet; }\end{array}$ & -2 & 2 & 2 & -8 \\
\hline $\begin{array}{l}\text { 5- Serviço de alimentação a lá carte prestado pelo restaurante: Geração de } \\
\text { Resíduos orgânicos deixados pelos clientes nas sobras dos pratos; }\end{array}$ & -2 & 2 & 1 & -4 \\
\hline $\begin{array}{l}\text { 6- Materiais recicláveis de consumo e higiene descartados pelos clientes após o } \\
\text { uso: materiais avulsos que os clientes tem acesso e que gera resíduo sendo } \\
\text { descartado no lixo comum; }\end{array}$ & -3 & 3 & 4 & -36 \\
\hline TOTAL DO IMPACTO & & & & -33 \\
\hline
\end{tabular}

Legenda: *O valor VRG pode variar de -125 a +125 , tendo como o ideal, valores próximos à zero.

\section{Percepção Socioambiental dos Colaboradores}

A percepção socioambiental dos colaboradores do RE foi verificada mediante aplicação do questionário A (Blocos I, II, III e IV) com questões que identificaram o conhecimento e o comportamento prósocial e pró-ambiental. Este questionário foi aplicado nos 13 funcionários dos diversos setores, sendo quatro do sexo masculino e nove do sexo feminino com idade entre 20 a 49 anos.

O Bloco I do questionário analisou o Comportamento Ecológico apresentando uma média geral de 3,06. Na análise individual por questão, apresentada na tabela 2 , as maiores pontuações foram de 5,$85 ; 5,54$; 5,54 e 5,15, para as questões 14,10,25, 26 respectivamente, (Guardo o papel que não quero mais na bolsa, quando não encontro uma lixeira por perto; Ajudo a manter as ruas limpas; Apago a luz quando saiu de ambientes vazios; e Evito desperdício de energia).

Um estudo realizado por Almeida et al. (2015) com alunos pós-graduando, obtiveram índices semelhantes para as mesmas questões (respectivamente 5,$71 ; 5,16 ; 5,20 ; 5,03$ ), no entanto, no presente trabalho, os colaboradores participantes da pesquisa possuíam apenas nível médio. Já o estudo de Beuron et al. (2012), aplicado em colaboradores com ensino médio de uma empresa inserida no contexto da sustentabilidade, apresentou resultados inferiores de comportamento ecológico para as mesmas perguntas $(4,62 ; 4,39 ; 5,21 ; 5,02)$. Isso indica que os colaboradores desta pesquisa, mesmo com nível inferior de escolaridade; e oriundo de empresa não inserida no contexto da sustentabilidade, obtiveram índices semelhantes (ALMEIDA et al., 2015), ou até mesmo superiores aos demais autores (BEURON et al., 2012).

Por outro lado, em três questões, todos os entrevistados responderam à alternativa 'nunca', apresentando consequentemente as menores pontuações, com média inferior a 1,00, sendo as questões 5 , 17, 22, respectivamente: 'Dou todo dinheiro que posso para ONG ambientalista', 'Faço trabalho voluntário para um grupo ambiental' e 'Quando não encontro lixeiras por perto, jogo latas vazias no chão', sendo que para as duas últimas a resposta 'discordo totalmente' foi a mais relatada. Esses índices de concordância com as três afirmativas foram inferiores aos encontrados no estudo por Beuron et al. (2012) $(1,24,1,76,1,40$, respectivamente) e Almeida et al. (2015) (respectivamente: 1,40, 1,59, 1,24). Essa baixa concordância encontrada no presente trabalho é um achado positivo, pois demonstra a baixa desejabilidade social 
encontrada neste questionário, ou seja, os participantes não tenderam a escolher as respostas consideradas mais aceitáveis ou aprovadas socialmente.

Além disso, esses índices baixos apontam que muitos comportamentos ecológicos não fazem parte da rotina dos indivíduos, mesmo declarando muitos ainda não praticam ações de comportamento ecológico (BEURON et al., 2012). O bloco II do questionário A analisou o Comportamento Social (tabela 3), do novo paradigma ecológico. No grupo de colaboradores do RE onde foi aplicado o questionário a escala apresentou uma média geral de 2,72, inferior ao encontrado em um estudo $(3,98)$ com indivíduos de diferentes formações e ocupações (professores, pesquisadores, estudantes e público em geral) das diferentes regiões brasileiras (SILVA FILHO et al., 2010).

Destaca-se ainda, que no bloco II as maiores pontuações observadas foram às assertivas 'A humanidade estão abusando seriamente do ambiente' e 'As plantas e os animais têm o mesmo direito a existir que os seres humanos', com 3,62 pontos cada (tabela 3). Outro trabalho realizado com Universitários brasileiros indicou a preferência de 56\% destas duas questões supracitadas (GORNI et al., 2011).

Por outro lado, as questões do bloco II que apresentam as menores pontuações foram 'O equilíbrio da natureza é bastante forte para suportar o impacto dos países industrializados' e 'Os seres humanos existem para dominar o resto da natureza', sendo que para ambas, a pontuação média foi de 2,00, valores baixos como aos encontrado em outro estudo com universitários $(1,69)$ (TAMBOSI et al., 2014). Estes resultados sugerem que o pensamento de dominação do homem sobre a natureza é condenado pelos participantes da pesquisa, demonstrando que os indivíduos estão mais conscientes sobre a sua atuação frente à natureza.

Tabela 2: Distribuição da estatística descritiva da escala dos Comportamentos Ecológicos e frequências das respostas bloco I do questionário ' $\mathrm{A}$ ', aplicado aos 13 colaboradores do RE. A pontuação de cada fator varia entre 1 a 6 pontos, a pontuação mais alta corresponde aos comportamentos mais frequentes e médias baixas significam não possuir o determinado comportamento.

\begin{tabular}{|c|c|c|c|c|c|c|c|}
\hline \multirow[t]{2}{*}{ Questão } & $\begin{array}{c}1 \\
\text { Nunca }\end{array}$ & $\begin{array}{c}2 \\
\text { Quase } \\
\text { nunca }\end{array}$ & $\begin{array}{c}3 \\
\text { Algumas } \\
\text { vezes } \\
\end{array}$ & $\begin{array}{c}4 \\
\text { Muitas } \\
\text { vezes }\end{array}$ & $\begin{array}{c}5 \\
\text { Quase } \\
\text { sempre }\end{array}$ & $\begin{array}{c}6 \\
\text { Sempre }\end{array}$ & \multirow[t]{2}{*}{ Média } \\
\hline & \multicolumn{6}{|c|}{$\mathrm{n}(\%)$} & \\
\hline Jogo todo tipo de lixo em qualquer lixeira. & $2(15,38)$ & $4(30,77)$ & $6(46,15)$ & $0(0)$ & $1(7,69)$ & $0(0)$ & 2,54 \\
\hline $\begin{array}{l}\text { Providenciei uma lixeira específica para cada tipo de lixo em minha } \\
\text { casa. }\end{array}$ & $3(23,08)$ & $3(23,08)$ & $3(23,08)$ & $\begin{array}{c}2 \\
(15,38)\end{array}$ & $1(7,69)$ & $1(7,69)$ & 2,85 \\
\hline Deixo a torneira aberta durante todo o tempo do banho. & $5(38,46)$ & $1(7,69)$ & $1(7,69)$ & $\begin{array}{c}2 \\
(15,38) \\
\end{array}$ & $1(7,69)$ & $\begin{array}{c}3 \\
(23,08) \\
\end{array}$ & 3,15 \\
\hline Evito jogar papel no chão. & $3(23,08)$ & $0(0)$ & $1(7,69)$ & $0(0)$ & $0(0)$ & $\begin{array}{c}9 \\
(69,23)\end{array}$ & 4,62 \\
\hline Dou todo dinheiro que posso para ONG ambientalista. & $13(100)$ & $0(0)$ & $0(0)$ & $0(0)$ & $0(0)$ & $0(0)$ & 1,00 \\
\hline Em casa, deixo as luzes acessas em ambientes não usados. & $7(53,85)$ & $2(15,38)$ & $1(7,69)$ & $\begin{array}{c}1 \\
(7,69) \\
\end{array}$ & $1(7,69)$ & $1(7,69)$ & 2,23 \\
\hline Falo sobre a importância do meio ambiente com as pessoas. & $2(15,38)$ & $2(15,38)$ & $8(61,54)$ & $\begin{array}{c}1 \\
(7,69) \\
\end{array}$ & $0(0)$ & $0(0)$ & 2,62 \\
\hline Abro a geladeira e fico olhando dentro quando não sei o que quero. & $2(15,38)$ & $4(30,77)$ & $3(23,08)$ & $\begin{array}{c}1 \\
(7,69)\end{array}$ & $1(7,69)$ & $\begin{array}{c}2 \\
(15,38)\end{array}$ & 3,08 \\
\hline Evito desperdício dos recursos naturais. & $0(0)$ & $1(7,69)$ & $2(15,38)$ & $\begin{array}{c}2 \\
(15,38)\end{array}$ & $\begin{array}{c}6 \\
(46,15)\end{array}$ & $\begin{array}{c}2 \\
(15,38)\end{array}$ & 4,46 \\
\hline Ajudo a manter as ruas limpas. & $0(0)$ & $1(7,69)$ & $0(0)$ & $0(0)$ & $\begin{array}{c}2 \\
(15,38) \\
\end{array}$ & $\begin{array}{c}10 \\
(76,92) \\
\end{array}$ & 5,54 \\
\hline Evito comprar produtos que são feitos de plástico. & $5(38,46)$ & $2(15,38)$ & $3(23,08)$ & $\begin{array}{c}2 \\
(15,38) \\
\end{array}$ & $0(0)$ & $1(7,69)$ & 2,46 \\
\hline Enquanto escovo os dentes deixo a torneira aberta. & $7(53,85)$ & $2(15,38)$ & $2(15,38)$ & $0(0)$ & $0(0)$ & $\begin{array}{c}2 \\
(15,38) \\
\end{array}$ & 2,23 \\
\hline
\end{tabular}




\begin{tabular}{|c|c|c|c|c|c|c|c|}
\hline Separo o lixo orgânico do reciclável. & $3(23,08)$ & $0(0)$ & $2(15,38)$ & \begin{tabular}{c|c|}
2 \\
$(15,38)$
\end{tabular} & $\begin{array}{c}2 \\
(15,38) \\
\end{array}$ & $\begin{array}{c}4 \\
(30,77) \\
\end{array}$ & 3,92 \\
\hline $\begin{array}{l}\text { Guardo papel que não quero na bolsa, quando não encontro uma } \\
\text { lixeira. }\end{array}$ & $0(0)$ & $0(0)$ & $0(0)$ & \begin{tabular}{c|c}
1 \\
$(7,69)$
\end{tabular} & $0(0)$ & $\begin{array}{c}12 \\
(92,31) \\
\end{array}$ & 5,85 \\
\hline Evito comer alimentos que contenham conservantes ou agrotóxicos. & $1(7,69)$ & $3(23,08)$ & $2(15,38)$ & \begin{tabular}{c|c|}
2 \\
$(15,38)$
\end{tabular} & $\begin{array}{c}3 \\
(23,08)\end{array}$ & $\begin{array}{c}2 \\
(15,38) \\
\end{array}$ & 3,69 \\
\hline Entrego papéis para reciclagem. & $7(53,85)$ & $0(0)$ & $1(7,69)$ & \begin{tabular}{c|c}
1 \\
$(7,69)$
\end{tabular} & $\begin{array}{c}2 \\
(15,38)\end{array}$ & $\begin{array}{c}2 \\
(15,38)\end{array}$ & 2,77 \\
\hline Faço trabalho voluntário para um grupo ambiental. & $13(100)$ & $0(0)$ & $0(0)$ & $0(0)$ & $0(0)$ & $0(0)$ & 1,00 \\
\hline Quando estou tomando banho, fecho a torneira para me ensaboar. & $9(69,23)$ & $0(0)$ & $1(7,69)$ & $0(0)$ & $\begin{array}{c}3 \\
(23,08) \\
\end{array}$ & $0(0)$ & 2,08 \\
\hline Economizo água quando possível. & $1(7,69)$ & $0(0)$ & $2(15,38)$ & $\begin{array}{c}1 \\
(7,69)\end{array}$ & $\begin{array}{c}2 \\
(15,38) \\
\end{array}$ & $\begin{array}{c}7 \\
(53,85) \\
\end{array}$ & 4,85 \\
\hline Quando vejo alguém jogando papel na rua, pego e jogo na lixeira. & $6(46,15)$ & $1(7,69)$ & $2(15,38)$ & \begin{tabular}{c|c}
2 \\
$(15,38)$
\end{tabular} & $1(7,69)$ & $1(7,69)$ & 2,54 \\
\hline Colaboro com a preservação da cidade onde vivo. & $1(7,69)$ & $0(0)$ & $3(23,08)$ & $\begin{array}{c}1 \\
(7,69) \\
\end{array}$ & $\begin{array}{c}2 \\
(15,38) \\
\end{array}$ & $\begin{array}{c}6 \\
(46,15) \\
\end{array}$ & 4,62 \\
\hline Quando não encontro lixeiras, jogo latas vazias no chão. & $13(100)$ & $0(0)$ & $0(0)$ & $0(0)$ & $0(0)$ & $0(0)$ & 1,00 \\
\hline Evito usar produtos fabricados por uma empresa poluidoras. & $5(38,46)$ & $1(7,69)$ & $1(7,69)$ & $\begin{array}{c}1 \\
(7,69)\end{array}$ & $\begin{array}{c}2 \\
(15,38) \\
\end{array}$ & $\begin{array}{c}3 \\
(23,08) \\
\end{array}$ & 3,23 \\
\hline Participo de manifestações públicas para defender o ambiente. & $11(84,62)$ & $1(7,69)$ & $1(7,69)$ & $0(0)$ & $0(0)$ & $0(0)$ & 1,23 \\
\hline Apago a luz quando saiu de ambientes vazios. & $0(0)$ & $0(0)$ & $1(7,69)$ & $0(0)$ & $\begin{array}{c}3 \\
(23,08) \\
\end{array}$ & $\begin{array}{c}9 \\
(69,23) \\
\end{array}$ & 5,54 \\
\hline Evito desperdício de energia. & $0(0)$ & $0(0)$ & $1(7,69)$ & \begin{tabular}{c|c}
2 \\
$(15,38)$
\end{tabular} & $\begin{array}{c}4 \\
(30,77) \\
\end{array}$ & $\begin{array}{c}6 \\
(46,15) \\
\end{array}$ & 5,15 \\
\hline Evito comer alimentos transgênicos. & $5(38,46)$ & $1(7,69)$ & $2(15,38)$ & \begin{tabular}{c|c|}
2 \\
$(15,38)$ \\
\end{tabular} & $\begin{array}{c}3 \\
(23,08) \\
\end{array}$ & $0(0)$ & 2,77 \\
\hline $\begin{array}{l}\text { Quando abro a geladeira já sei o que vou pegar, evitando deixar } \\
\text { aberta. }\end{array}$ & $2(15,38)$ & $2(15,38)$ & $3(23,08)$ & $0(0)$ & $\begin{array}{c}2 \\
(15,38)\end{array}$ & $\begin{array}{c}4 \\
(30,77) \\
\end{array}$ & 3,77 \\
\hline $\begin{array}{l}\text { Mobilizo as pessoas nos cuidados na conservação dos espaços } \\
\text { públicos. }\end{array}$ & $5(38,46)$ & $1(7,69)$ & $4(30,77)$ & $\begin{array}{c}1 \\
(7,69)\end{array}$ & $1(7,69)$ & $1(7,69)$ & 2,62 \\
\hline $\begin{array}{l}\text { Compro comida sem me preocupar se têm conservantes ou } \\
\text { agrotóxicos. }\end{array}$ & $4(30,77)$ & $1(7,69)$ & $2(15,38)$ & $\begin{array}{c}1 \\
(7,69) \\
\end{array}$ & $\begin{array}{c}4 \\
(30,77) \\
\end{array}$ & $1(7,69)$ & 3,23 \\
\hline Deixo a televisão ligada mesmo sem ninguém a & $(46,15)$ & $1(7,69)$ & $2(15,38)$ & \begin{tabular}{c|c}
2 \\
$(15,38)$
\end{tabular} & $1(7,69)$ & $1(7,69)$ & 2,54 \\
\hline Entrego as pilhas usadas nos postos de coleta. & $10(76,92)$ & $0(0)$ & $3(23,08)$ & $0(0)$ & $0(0)$ & $0(0)$ & 1,46 \\
\hline Participo de atividades que cuidam do meio ambiente. & $11(84,62)$ & $1(7,69)$ & $1(7,69)$ & $0(0)$ & $0(0)$ & $0(0)$ & 1,23 \\
\hline $\begin{array}{l}\text { Evito ligar vários aparelhos elétricos ao mesmo tempo nos horários } \\
\text { de maior consumo de energia. }\end{array}$ & 6) & $2(15,38)$ & $3(23,08)$ & $\begin{array}{c}2 \\
(15,38)\end{array}$ & $0(0)$ & $1(7,69)$ & 2,46 \\
\hline Média geral do Bloco I & & & & & & & 3,06 \\
\hline
\end{tabular}

Tabela 3: Distribuição de frequências das respostas da escala de Comportamento Social dos participantes da pesquisa das questões do bloco II do questionário, onde 1 é designado para a resposta "discordo totalmente; 2 para "discordo parcialmente"; 3 para "concordo parcialmente" e 4 para "concordo totalmente. Sendo assim, a pontuação de cada fator varia entre 1 a 4 pontos, e quanto maior o valor, maior é a concordância com as questões que o compõem.

\begin{tabular}{|c|c|c|c|c|c|}
\hline \multirow[t]{2}{*}{ Assertivas } & $\begin{array}{c}1 \\
\text { Discordo } \\
\text { totalmente }\end{array}$ & $\begin{array}{c}2 \\
\text { Discordo } \\
\text { parcialmente }\end{array}$ & $\begin{array}{c}3 \\
\text { Concordo } \\
\text { parcialmente }\end{array}$ & $\begin{array}{c}4 \\
\text { Concordo } \\
\text { totalmente }\end{array}$ & \multirow[t]{2}{*}{ Média } \\
\hline & \multicolumn{4}{|c|}{$n(\%)$} & \\
\hline $\begin{array}{l}\text { Está aproximando do número máx. de pessoas que a terra } \\
\text { suportar. }\end{array}$ & $4(30,77)$ & $4(30,77)$ & $5(38,46)$ & $0(0)$ & 2,08 \\
\hline $\begin{array}{l}\text { Os seres humanos têm o direito de modificar o ambiente natural } \\
\text { para adequá-lo às suas necessidades. }\end{array}$ & $3(23,08)$ & $6(46,15)$ & $3(23,08)$ & $1(7,69)$ & 2,15 \\
\hline $\begin{array}{l}\text { Quando os seres humanos interferem na natureza, provocam com } \\
\text { frequência consequências desastrosas. }\end{array}$ & $1(7,69)$ & $0(0)$ & $4(30,77)$ & $8(61,54)$ & 3,46 \\
\hline $\begin{array}{l}\text { A genialidade humana assegura que a Terra nunca se tornará } \\
\text { inabitável. }\end{array}$ & $5(38,46)$ & $4(30,77)$ & $2(15,38)$ & $2(15,38)$ & 2,08 \\
\hline A humanidade está abusando seriamente do ambiente. & $0(0)$ & $0(0)$ & $5(38,46)$ & $8(61,54)$ & 3,62 \\
\hline $\begin{array}{l}\text { A Terra terá quantidade suficiente de recursos naturais se } \\
\text { aprendemos a aproveitá-los. }\end{array}$ & $3(23,08)$ & $0(0)$ & $2(15,38)$ & $8(61,54)$ & 3,15 \\
\hline As plantas/animais têm o mesmo direito a existir que os humanos. & $0(0)$ & $0(0)$ & $5(38,46)$ & $8(61,54)$ & 3,62 \\
\hline $\begin{array}{l}\text { O equilíbrio da natureza é bastante forte para suportar o impacto } \\
\text { dos países industrializados. }\end{array}$ & $5(38,46)$ & $4(30,77)$ & $3(23,08)$ & $1(7,69)$ & 2,00 \\
\hline $\begin{array}{l}\text { Apesar de nossas habilidades humanas especiais, ainda estamos } \\
\text { sujeitos às leis da natureza. }\end{array}$ & $1(7,69)$ & $0(0)$ & $5(38,46)$ & $7(53,85)$ & 3,38 \\
\hline $\begin{array}{l}\text { A assim chamada 'crise ecológica' que a humanidade enfrenta tem } \\
\text { sido divulgada com exagero. }\end{array}$ & $4(30,77)$ & $5(38,46)$ & $3(23,08)$ & $1(7,69)$ & 2,08 \\
\hline A Terra é como uma espaçonave com espaço e recursos limitados. & $2(15,38)$ & $4(30,77)$ & $5(38,46)$ & $2(15,38)$ & 2,54 \\
\hline Os seres humanos existem para dominar o resto da natureza. & $6(46,15)$ & $3(23,08)$ & $2(15,38)$ & $2(15,38)$ & 2,00 \\
\hline O equilíbrio da natureza é muito frágil e facilmente alterável. & $2(15,38)$ & $1(7,69)$ & $5(38,46)$ & $5(38,46)$ & 3,00 \\
\hline $\begin{array}{l}\text { Um dia a humanidade aprenderá o suficiente sobre o } \\
\text { funcionamento da natureza a ponto de poder controlá-la. }\end{array}$ & $4(30,77)$ & $2(15,38)$ & $3(23,08)$ & $4(30,77)$ & 2,54 \\
\hline
\end{tabular}




\begin{tabular}{|l|c|c|c|c|}
\hline $\begin{array}{l}\text { Se as coisas continuarem assim, logo sofreremos uma grande } \\
\text { catástrofe ecológica. }\end{array}$ & $2(15,38)$ & $1(7,69)$ & $2(15,38)$ & $8(61,54)$ \\
\hline Média geral do Bloco II & & 3,23 \\
\hline
\end{tabular}

O Questionário ' $A$ ' do Bloco III analisou as questões relacionadas ao individualismo e o coletivismo. Este bloco, que se refere ao bem-estar individual ou em grupo, apresentou uma média geral elevada de 4,97 (escala que varia de 1 a 7 pontos). As afirmativas com maiores pontuações foram 'O bem-estar dos meus companheiros de trabalho é importante para mim', e 'Sentiria-me orgulhoso se um companheiro de trabalho ganhasse um prêmio' atingindo os maiores índices (6,38 e 6,46 respectivamente) (tabela 4).

Um estudo realizado com 62 sociedades relata que o coletivismo institucional incentiva à distribuição coletiva de recursos e ações, indicando que esses indivíduos têm preocupações mais fortes sobre a sustentabilidade, sendo mais pró-ambientais (HOUSE et al., 2004). Com isso, pode-se fundamentar que no presente estudo, os indivíduos mostram-se preocupados com estas temáticas ambientais. Outro estudo, realizado com estudantes americanos e japoneses de graduação, corroborou com esta fundamentação que os conceitos do Individualismo e o Coletivismo são fortemente intercorrelacionados na percepção ambiental e que existia uma diferença entre a percepção de seriedade das questões ambientais e a disposição de contribuir com dinheiro para prevenir o meio ambiente, se tornando mais forte em sociedades individualistas do que nas sociedades coletivistas (EOM et al., 2016).

Um estudo realizado com 62 sociedades relata que o coletivismo institucional incentiva à distribuição coletiva de recursos e ações, indicando que esses indivíduos têm preocupações mais fortes sobre a sustentabilidade, sendo mais pró-ambientais (HOUSE et al., 2004). Com isso, pode-se fundamentar que no presente estudo, os indivíduos mostram-se preocupados com estas temáticas ambientais. Outro estudo, realizado com estudantes americanos e japoneses de graduação, corroborou com esta fundamentação que os conceitos do Individualismo e o Coletivismo são fortemente intercorrelacionados na percepção ambiental e que existia uma diferença entre a percepção de seriedade das questões ambientais e a disposição de contribuir com dinheiro para prevenir o meio ambiente, se tornando mais forte em sociedades individualistas do que nas sociedades coletivistas (EOM et al., 2016).

O questionário 'A' bloco IV analisou o Conhecimento socioambiental e apresentou uma média geral de 3,17. Segundo o Ministério do Meio Ambiente, todos são responsáveis pela preservação ambiental: governos, empresas e cada cidadão são responsáveis participando assim do processo de transformação e conhecimento socioambiental.

Para Leff (2001), a conscientização deve considerar as variáveis culturais e estilos de vida como parte da racionalidade ambiental. Já Morin (2002) relata que o conhecimento socioambiental é uma relação integral, contextualizada, interrelacionada e proposta para o saber. A literatura relata ainda que existem múltiplos indicadores que influenciam o conhecimento, o comprometimento e a conscientização do consumidor ecologicamente, visto que os consumidores se voltam a pesar nos benefícios ambientais e econômicos quando escolhem opções verdes (MANIATIS, 2015). 
Na tabela 5, nota-se que a maior pontuação média foi observada para a afirmativa 'Antes de pensar em me divertir tenho que cumprir com os prazos que estão próximos de vencer e fazer as tarefas necessárias' $(4,38)$. Por outro lado, as questões que apresentam as menores pontuações médias, sendo de $(1,85)$ cada, foram 'Já que o que tem de acontecer vai mesmo acontecer, o que eu fizer não importa' e 'Não faz sentido se preocupar com o futuro, já que no final das contas não há nada que eu possa fazer a respeito' indicando o comprometimento socioambiental dos colaboradores. Esses resultados validam a concepção de que na medida em que os consumidores obtêm mais informações sobre questões ambientais, suas atitudes vão se modificando em relação a esses mesmos assuntos, o que, por sua vez, os leva a modificar seus comportamentos sociais (POLONSKY et al., 2012).

Tabela 4: Distribuição de frequências das respostas da escala do Individualismo e Coletivismo das questões do bloco III do questionário onde os colaboradores expressam o quanto estão de acordo ou desacordo. Sendo assim, a pontuação de cada fator varia entre 1 a 7 pontos, e quanto maior o valor, maior é a concordância com as questões que o compõem. Tem-se que a média geral d Bloco III foi 4,97.

\begin{tabular}{|c|c|c|c|c|c|c|c|c|}
\hline \multirow{2}{*}{ Afirmativa $\mathrm{n}(\%)$} & 1 & 2 & 3 & 4 & 5 & 6 & 7 & \multirow{2}{*}{ Média } \\
\hline & \multicolumn{2}{|c|}{ Discordo totalmente } & \multicolumn{2}{|c|}{ Indiferente } & \multicolumn{3}{|c|}{ Concordo plenamente } & \\
\hline $\begin{array}{l}\text { É importante para mim respeitar as decisões tomadas pelo meu } \\
\text { grupo. }\end{array}$ & $0(0)$ & $0(0)$ & $0(0)$ & $\begin{array}{c}2 \\
(15,38) \\
\end{array}$ & $\begin{array}{c}3 \\
(23,08)\end{array}$ & $\begin{array}{c}5 \\
(38,46)\end{array}$ & $\begin{array}{c}3 \\
(23,08)\end{array}$ & 5,69 \\
\hline Sinto-me muito bem quando colaboro com os outros. & $0(0)$ & $0(0)$ & $0(0)$ & $0(0)$ & $\begin{array}{c}3 \\
(23,08)\end{array}$ & $\begin{array}{c}4 \\
(30,77)\end{array}$ & $\begin{array}{c}6 \\
(46,15)\end{array}$ & 6,23 \\
\hline Com frequência faço 'minhas próprias coisas'. & $0(0)$ & $0(0)$ & $0(0)$ & $\begin{array}{c}1 \\
(7,69)\end{array}$ & $\begin{array}{c}2 \\
(15,38)\end{array}$ & $\begin{array}{c}6 \\
(46,15)\end{array}$ & $\begin{array}{c}4 \\
(30,77)\end{array}$ & 6,00 \\
\hline Pais e filhos devem estar juntos sempre que possível. & $0(0)$ & $0(0)$ & $1(7,69)$ & $0(0)$ & $\begin{array}{c}2 \\
(15,38)\end{array}$ & $\begin{array}{c}4 \\
(30,77)\end{array}$ & $\begin{array}{c}6 \\
(46,15)\end{array}$ & 6,08 \\
\hline Triunfar é tudo. & $2(15,38)$ & $2(15,38)$ & $0(0)$ & $\begin{array}{c}4 \\
(30,77) \\
\end{array}$ & $\begin{array}{c}2 \\
(15,38)\end{array}$ & $\begin{array}{c}3 \\
(23,08)\end{array}$ & $0(0)$ & 3,85 \\
\hline $\begin{array}{l}\text { Os membros da família devem estar juntos, não importa } \\
\text { quanto sacrifício seja necessário. }\end{array}$ & $0(0)$ & $0(0)$ & $1(7,69)$ & $\begin{array}{c}2 \\
(15,38)\end{array}$ & $\begin{array}{c}2 \\
(15,38)\end{array}$ & $\begin{array}{c}4 \\
(30,77)\end{array}$ & $\begin{array}{c}4 \\
(30,77)\end{array}$ & 5,62 \\
\hline Preferiria depender de mim mesmo do que dos demais. & $2(15,38)$ & $0(0)$ & $0(0)$ & $\begin{array}{c}2 \\
(15,38) \\
\end{array}$ & $\begin{array}{c}5 \\
(38,46) \\
\end{array}$ & $\begin{array}{c}1 \\
(7,69) \\
\end{array}$ & $\begin{array}{c}3 \\
(23,08) \\
\end{array}$ & 4,77 \\
\hline Para mim, prazer significa passar o tempo com os demais. & $2(15,38)$ & $2(15,38)$ & $1(7,69)$ & $\begin{array}{c}2 \\
(15,38) \\
\end{array}$ & $\begin{array}{c}3 \\
(23,08) \\
\end{array}$ & $\begin{array}{c}1 \\
(7,69) \\
\end{array}$ & $\begin{array}{c}2 \\
(15,38) \\
\end{array}$ & 4,00 \\
\hline $\begin{array}{l}\text { Na maior parte do tempo, confio em mim mesmo; raramente } \\
\text { confio nos demais. }\end{array}$ & $2(15,38)$ & $0(0)$ & $3(23,08)$ & $\begin{array}{c}4 \\
(30,77)\end{array}$ & $\begin{array}{c}2 \\
(15,38)\end{array}$ & $\begin{array}{c}1 \\
(7,69)\end{array}$ & $\begin{array}{c}1 \\
(7,69)\end{array}$ & 3,85 \\
\hline $\begin{array}{l}\text { Quando outra pessoa faz alguma coisa melhor que eu, fico } \\
\text { tenso e chateado. }\end{array}$ & $6(46,15)$ & $2(15,38)$ & $3(23,08)$ & $\begin{array}{c}2 \\
(15,38) \\
\end{array}$ & $0(0)$ & $0(0)$ & $0(0)$ & 2,08 \\
\hline $\begin{array}{l}\text { É meu dever cuidar da minha família, mesmo quando tenho } \\
\text { que sacrificar meus interesses. }\end{array}$ & $1(7,69)$ & $0(0)$ & $1(7,69)$ & $\begin{array}{c}1 \\
(7,69)\end{array}$ & $\begin{array}{c}4 \\
(30,77)\end{array}$ & $\begin{array}{c}3 \\
(23,08)\end{array}$ & $\begin{array}{c}3 \\
(23,08)\end{array}$ & 5,15 \\
\hline $\begin{array}{l}\text { É importante, para mim, fazer meu trabalho melhor que os } \\
\text { demais. }\end{array}$ & $1(7,69)$ & $1(7,69)$ & $2(15,38)$ & $\begin{array}{c}2 \\
(15,38)\end{array}$ & $\begin{array}{c}3 \\
(23,08)\end{array}$ & $\begin{array}{c}4 \\
(30,77)\end{array}$ & $0(0)$ & 4,31 \\
\hline $\begin{array}{l}\text { O bem-estar dos meus companheiros de trabalho é importante } \\
\text { para mim. }\end{array}$ & $0(0)$ & $0(0)$ & $0(0)$ & $0(0)$ & $\begin{array}{c}2 \\
(15,38) \\
\end{array}$ & $\begin{array}{c}4 \\
(30,77) \\
\end{array}$ & $\begin{array}{c}7 \\
(53,85) \\
\end{array}$ & 6,38 \\
\hline $\begin{array}{l}\text { Independente dos demais, minha identidade pessoal é muito } \\
\text { importante para mim. }\end{array}$ & $1(7,69)$ & $1(7,69)$ & $1(7,69)$ & $\begin{array}{c}1 \\
(7,69)\end{array}$ & $\begin{array}{c}2 \\
(15,38)\end{array}$ & $0(0)$ & $\begin{array}{c}7 \\
(53,85)\end{array}$ & 5,31 \\
\hline A competição é a lei da natureza. & $4(30,77)$ & $0(0)$ & $2(15,38)$ & $\begin{array}{c}1 \\
(7,69)\end{array}$ & $\begin{array}{c}3 \\
(23,08)\end{array}$ & $\begin{array}{c}1 \\
(7,69)\end{array}$ & $\begin{array}{c}2 \\
(15,38)\end{array}$ & 3,77 \\
\hline $\begin{array}{l}\text { Sentiria-me orgulhoso se um companheiro de trabalho } \\
\text { ganhasse um prêmio. }\end{array}$ & $1(7,69)$ & $0(0)$ & $0(0)$ & $0(0)$ & $0(0)$ & $\begin{array}{c}1 \\
(7,69)\end{array}$ & $\begin{array}{c}11 \\
(84,62)\end{array}$ & 6,46 \\
\hline
\end{tabular}

$\mathrm{Na}$ análise das médias por bloco avaliativo (tabela 6) obteve-se resultados medianos para o comportamento ecológico enquanto para os demais blocos (escala de comportamento social, escala do individualismo e coletivismo e para a escala de comportamento socioambiental) os resultados foram superiores à média da escala Likert correspondente. Essa constatação indicou a baixa frequência de comportamento ecológico entre os colaboradores, apontando que mesmo tendo preocupações de coletividade (Bloco III) e de comportamento socioambiental (Bloco IV) os participantes tinham comportamentos ecológicos apenas algumas vezes. 
Tabela 5 - Distribuição estatística de frequências das respostas da escala de Comportamento Socioambiental dos participantes da pesquisa das questões do bloco IV do questionário, onde 1 e 2 é designado para a resposta 'bastante inaplicável'; 3 para 'neutro'; 4 e 5 para 'bastante aplicável'. Quanto maior o valor, maior é a concordância com as questões que o compõem. Tem-se que a moda geral do Bloco IV foi 3,17.

\begin{tabular}{|c|c|c|c|c|c|c|}
\hline \multirow{3}{*}{ Questão } & 1 & 2 & 3 & 4 & 5 & \multirow{3}{*}{ Média } \\
\hline & $\begin{array}{l}\text { Bastante } \\
\text { inaplicável }\end{array}$ & \multicolumn{2}{|c|}{ Neutro } & \multicolumn{2}{|c|}{ Bastante aplicável } & \\
\hline & \multicolumn{5}{|c|}{$\mathrm{n}(\%)$} & \\
\hline Acho que as pessoas deveriam planejar o dia de manhã & $1(7,69)$ & $\begin{array}{c}1 \\
(7,69) \\
\end{array}$ & \begin{tabular}{c|}
4 \\
$(30,77)$ \\
\end{tabular} & $4(30,77)$ & $\begin{array}{c}3 \\
(23,08) \\
\end{array}$ & 3,54 \\
\hline Eu faço coisas sem pensar. & $2(15,38)$ & $\begin{array}{c}6 \\
(46,15) \\
\end{array}$ & $\begin{array}{c}3 \\
(23,08)\end{array}$ & $2(15,38)$ & $0(0)$ & 2,38 \\
\hline $\begin{array}{l}\text { Quando eu quero conseguir alguma coisa, traço metas e avalio os } \\
\text { recursos necessários para obter o que desejo. }\end{array}$ & $0(0)$ & $0(0)$ & $\begin{array}{c}2 \\
(15,38)\end{array}$ & $5(38,46)$ & $\begin{array}{c}6 \\
(46,15)\end{array}$ & 4,31 \\
\hline $\begin{array}{l}\text { Já que o que tem de acontecer vai mesmo acontecer, o que eu fizer não } \\
\text { importa. }\end{array}$ & $5(38,46)$ & $\begin{array}{c}6 \\
(46,15) \\
\end{array}$ & $\begin{array}{c}1 \\
(7,69)\end{array}$ & $1(7,69)$ & $0(0)$ & 1,85 \\
\hline $\begin{array}{l}\text { Antes de pensas em me divertir tenho que cumprir com os prazos e fazer } \\
\text { as tarefas. }\end{array}$ & $1(7,69)$ & $0(0)$ & $0(0)$ & $4(30,77)$ & $\begin{array}{c}8 \\
(61,54) \\
\end{array}$ & 4,38 \\
\hline Eu tento viver minha vida o mais plenamente possível, um dia por vez. & $1(7,69)$ & $0(0)$ & $\begin{array}{c}1 \\
(7,69)\end{array}$ & $5(38,46)$ & $\begin{array}{c}6 \\
(46,15)\end{array}$ & 4,15 \\
\hline Eu cumpro minhas obrigações com amigos e autoridades no prazo certo. & $1(7,69)$ & $0(0)$ & $0(0)$ & $5(38,46)$ & $\begin{array}{c}7 \\
(53,85) \\
\end{array}$ & 4,31 \\
\hline Eu tomo decisões na hora (no calor do momento). & $3(23,08)$ & $\begin{array}{c}2 \\
(15,38) \\
\end{array}$ & $\begin{array}{c}6 \\
(46,15) \\
\end{array}$ & $1(7,69)$ & $\begin{array}{c}1 \\
(7,69) \\
\end{array}$ & 2,62 \\
\hline Eu vivo cada dia como ele é, não fico fazendo planos. & $2(15,38)$ & $\begin{array}{c}4 \\
(30,77) \\
\end{array}$ & $\begin{array}{c}3 \\
(23,08) \\
\end{array}$ & $2(15,38)$ & $\begin{array}{c}2 \\
(15,38)\end{array}$ & 2,85 \\
\hline É importante viver com emoção. & $1(7,69)$ & \begin{tabular}{|c|}
2 \\
$(15,38)$ \\
\end{tabular} & \begin{tabular}{c|}
3 \\
$(23,08)$ \\
\end{tabular} & $4(30,77)$ & \begin{tabular}{c|}
3 \\
$(23,08)$ \\
\end{tabular} & 3,46 \\
\hline Antes de tomar decisão, eu avalio custos e benefícios. & $0(0)$ & $\begin{array}{c}1 \\
(7,69) \\
\end{array}$ & $\begin{array}{c}1 \\
(7,69) \\
\end{array}$ & $5(38,46)$ & $\begin{array}{c}6 \\
(46,15)\end{array}$ & 4,23 \\
\hline Assumir riscos torna minha vida menos monótona. & $4(30,77)$ & $\begin{array}{c}1 \\
(7,69) \\
\end{array}$ & $\begin{array}{c}3 \\
(23,08) \\
\end{array}$ & $1(7,69)$ & $\begin{array}{c}4 \\
(30,77) \\
\end{array}$ & 3,00 \\
\hline $\begin{array}{l}\text { Para mim é mais importante aproveitar a vida do que apenas pensar } \\
\text { aonde vou chegar. }\end{array}$ & $3(23,08)$ & $\begin{array}{c}5 \\
(38,46) \\
\end{array}$ & $\begin{array}{c}3 \\
(23,08) \\
\end{array}$ & $1(7,69)$ & $\begin{array}{c}1 \\
(7,69) \\
\end{array}$ & 2,38 \\
\hline Incomoda-me chegar atrasado em compromissos. & $0(0)$ & \begin{tabular}{|c|}
2 \\
$(15,38)$ \\
\end{tabular} & $0(0)$ & $4(30,77)$ & \begin{tabular}{c|}
7 \\
$(53,85)$ \\
\end{tabular} & 4,23 \\
\hline $\begin{array}{l}\text { Não é possível realmente planejar para o futuro, porque as coisas mudam } \\
\text { muito. }\end{array}$ & $2(15,38)$ & $\begin{array}{c}3 \\
(23,08) \\
\end{array}$ & $\begin{array}{c}3 \\
(23,08) \\
\end{array}$ & $3(23,08)$ & $\begin{array}{c}2 \\
(15,38)\end{array}$ & 3,00 \\
\hline $\begin{array}{l}\text { Não faz sentido preocupar com o futuro, já que no final das contas não há } \\
\text { nada que eu possa fazer a respeito. }\end{array}$ & $5(38,46)$ & $\begin{array}{c}6 \\
(46,15) \\
\end{array}$ & $\begin{array}{c}1 \\
(7,69) \\
\end{array}$ & $1(7,69)$ & $0(0)$ & 1,85 \\
\hline Eu assumo riscos para colocar emoção em minha vida. & $4(30,77)$ & \begin{tabular}{c|}
3 \\
$(23,08)$ \\
\end{tabular} & \begin{tabular}{c|}
3 \\
$(23,08)$ \\
\end{tabular} & $2(15,38)$ & \begin{tabular}{c|c|}
1 \\
$(7,69)$ \\
\end{tabular} & 2,46 \\
\hline Eu faço listas das coisas que preciso fazer. & $1(7,69)$ & $\begin{array}{c}1 \\
(7,69) \\
\end{array}$ & \begin{tabular}{|c|}
2 \\
$(15,38)$ \\
\end{tabular} & $6(46,15)$ & \begin{tabular}{c|}
3 \\
$(23,08)$ \\
\end{tabular} & 3,69 \\
\hline Com frequência eu sigo meu coração mais que a cabeça. & $3(23,08)$ & $\begin{array}{c}1 \\
(7,69)\end{array}$ & $\begin{array}{c}5 \\
(38,46) \\
\end{array}$ & $1(7,69)$ & $\begin{array}{c}3 \\
(23,08) \\
\end{array}$ & 3,00 \\
\hline Eu me percebo envolvido pela emoção do momento. & $3(23,08)$ & \begin{tabular}{|c|}
4 \\
$(30,77)$ \\
\end{tabular} & \begin{tabular}{c|}
3 \\
$(23,08)$ \\
\end{tabular} & $3(23,08)$ & $0(0)$ & 2,46 \\
\hline $\begin{array}{l}\text { Eu prefiro a vida mais simples do passado, pois a vida de hoje é } \\
\text { complicada demais. }\end{array}$ & $3(23,08)$ & $\begin{array}{c}3 \\
(23,08) \\
\end{array}$ & $\begin{array}{c}3 \\
(23,08) \\
\end{array}$ & $3(23,08)$ & $\begin{array}{c}1 \\
(7,69) \\
\end{array}$ & 2,69 \\
\hline Sempre haverá tempo para colocar em dia meu trabalho. & $0(0)$ & $\begin{array}{c}2 \\
(15,38) \\
\end{array}$ & $\begin{array}{c}4 \\
(30,77) \\
\end{array}$ & $4(30,77)$ & $\begin{array}{c}3 \\
(23,08) \\
\end{array}$ & 3,62 \\
\hline $\begin{array}{l}\text { Se a tarefa for necessária para avançar, sigo trabalhando mesmo que ela } \\
\text { seja difícil ou desinteressante. }\end{array}$ & $0(0)$ & $0(0)$ & $\begin{array}{c}2 \\
(15,38) \\
\end{array}$ & $5(38,46)$ & $\begin{array}{c}6 \\
(46,15)\end{array}$ & 4,31 \\
\hline $\begin{array}{l}\text { Prefiro gastar o que eu ganhei, com prazeres de hoje, do que economizar } \\
\text { para o futuro. }\end{array}$ & $1(7,69)$ & \begin{tabular}{|c|}
4 \\
$(30,77)$ \\
\end{tabular} & $\begin{array}{c}6 \\
(46,15) \\
\end{array}$ & $2(15,38)$ & $0(0)$ & 2,69 \\
\hline A sorte costuma ser mais vantajosa do quero duro. & $4(30,77)$ & $\begin{array}{c}5 \\
(38,46) \\
\end{array}$ & $\begin{array}{c}4 \\
(30,77) \\
\end{array}$ & $0(0)$ & $0(0)$ & 2,00 \\
\hline
\end{tabular}

A maioria não providência uma lixeira específica para cada tipo de lixo em minha casa; não fala sobre a importância do meio ambiente com as pessoas; não evita comprar produtos que são feitos de plástico; quando alguém joga papel na rua, não pega e joga na lixeira; não evita usar produtos fabricados por uma empresa poluidora do meio ambiente; não entrega as pilhas usadas nos postos de coleta; não participo de atividades que cuidam do meio ambiente, entre outras. 
Tabela 6: Médias dos blocos I, II, III e IV do questionário A aplicado aos colaboradores do RE.

\begin{tabular}{|l|c|}
\hline \multicolumn{1}{|c|}{ Bloco } & Média \\
\hline Bloco I: Escala do Comportamento Ecológico & 3,06 \\
\hline Bloco II: Escala de Comportamento Social & 1 a 6 \\
\hline Bloco III: Escala do Individualismo e Coletivismo & 1 a 4 \\
\hline Bloco IV: Escala de Comportamento Socioambiental & 1 a 7 \\
\hline
\end{tabular}

\section{Percepção Socioambiental dos Clientes}

O total de clientes entrevistados foram 300 com idade entre 18 a 70 anos. Os clientes responderam 26 assertivas relacionadas com a percepção ambiental e a repercussão nas práticas de consumo. 0 questionário iniciava-se por questões sociodemográficas que indicavam o perfil dos clientes. Aproximadamente dois terços dos participantes da pesquisa (67,00\%) são do sexo feminino. A maioria dos entrevistados (67,33\%) possui 30 anos ou menos, enquanto apenas pouco mais de $10 \%$ possui idade superior a 40 anos. Também se verifica a predominância na amostra de indivíduos solteiros (64,33\%) e com ensino superior (87,67\%). Do total de entrevistados, 62,33\% eram alunos da Unicesumar, $28,33 \%$ colaboradores da instituição e 9,33\% clientes externos.

Foram avaliados sete fatores da percepção socioambiental dos clientes: 1) Preocupação Global e Local (PRGL), 2) Consumo Verde (CV), 3) Atitude Local (AL), 4) Decrescimento (DC), 5) Antropocentrismo (AT), 6) Crenças (CR), e 7) Controle do Crescimento Econômico. Os fatores indicaram que a maior parte das questões $(16 / 26)$ teve a resposta 'concordo totalmente' como a alternativa mais frequentemente citada entre os entrevistados, sendo que as maiores pontuações médias foram observadas para as afirmativas ' $O$ desmatamento das grandes florestas pode comprometer o futuro da humanidade' e 'A poluição dos rios e lagos poderá afetar a qualidade de vida dos seres humanos', com 4,78 e 4,86, respectivamente (tabela 8).

Por outro lado, as três questões que possuíam um caráter negativo em relação à preocupação ambiental foram as que apresentaram as menores pontuações médias, sendo de 2,58 ('Os seres humanos têm o direito de modificar o ambiente natural para atender às suas necessidades'), de 2,19 ('A humanidade foi criada para governar o resto da natureza'), e de 2,11 ('A humanidade não precisa se adaptar ao ambiente natural porque pode modificá-lo para atender suas necessidades'), sendo que para as duas últimas a resposta 'discordo totalmente' foi a mais relatada.

Em compensação, o estudo revelou uma baixa pontuação $(2,77)$ para uma afirmativa de denotação positiva ('Na escolha de um produto, dou prioridade mais a aspectos ambientais do que ao preço/qualidade'). No entanto esta afirmativa inseria aspectos econômicos junto ao socioambiental, demonstrando que a preocupação com os valores dos produtos supera as causas ambientais, bem como que os indivíduos não estão dispostos a renunciar determinados confortos e/ou produtos em detrimento ao meio ambiente.

Quando se calculou a média da pontuação por fator analisado (PR, CV, AL, DC, AT, CR, CE), a preocupação global e local foi o fator de maior preocupação para os indivíduos. Essa pontuação alta $(4,51$ $\pm 0,61$ ), indicando uma baixa dispersão dos dados em relação à média (tabela 8). A preocupação foi o conhecimento ambiental estão relacionados ao que as pessoas entendem sobre o meio ambiente em termos de como o produto é produzido, como isso afeta o meio ambiente e como a responsabilidade coletiva é necessária para o desenvolvimento sustentável (KAUFMANN et al., 2012). 
Um estudo de investigação bibliográfica indicou que os consumidores ignoravam a sustentabilidade ou o desenvolvimento sustentável no passado, no entanto o estudo relata que o interesse por práticas ambientalmente sustentáveis está crescendo e com isso influenciam positivamente a avaliação dos clientes (FINNEY, 2014). Outro estudo publicado na Austrália por Sarmiento et al. (2018) analisou as percepções dos clientes e expectativas de um restaurante ambientalmente sustentável e revelou que os clientes não estavam cientes dos impactos ambientais das operações dos restaurantes. No entanto, os clientes estavam dispostos a pagar uma taxa Premium se o restaurante tivesse práticas ambientais sustentáveis. A disposição de pagar agregou positivamente com o nível de educação do cliente.

Pode-se dizer que o comportamento do consumidor está gradativamente influenciado por valores ambientais ou "verdes" que motivam o que as pessoas compram e consomem (DOSZHANOV et al., 2015). Assim, o aumento do número de pessoas considerando a compra de alimentos 'amigos do meio ambiente' vem favorecendo as preocupações com sistemas produtivos mais limpos (SUKI, 2013). Analisado o fator Consumo Verde (CV) pode-se observar que a média foi de $3,56 \pm 0,87$, indicando um resultado baixo de dispersão dos dados em relação à média com coeficientes de variação em torno ou menos que 25\% (tabela 8). A média para consumo verde não é considerada alta, é mediana. Mesmo assim, indica que os consumidores estão adquirindo maior consciência da necessidade de adotar estilos de vida mais sustentáveis, no entanto ainda carecem de colocar em prática ações de compra e modo de vida mais sustentáveis. Uma pesquisa realizada por Namkung et al. (2013), em um restaurante americano com 512 clientes, mostrou que, certamente, eles são mais propensos a escolher um restaurante com uma imagem positiva mais forte. Isso mostra que o consumidor está à procura de organizações com rotulagem ambiental, ou seja, empresas que utilizam ferramentas que promovem o consumo sustentável (HALL, 2013).

Outro ponto importante refere-se ao incremento do comportamento pró-ambiental que pode ser aplicado para influenciar a demanda do consumidor para incentivar a compra de produtos mais sustentáveis (HALL, 2013). Um estudo de revisão sistemática da literatura nos principais veículos de publicação do Brasil, no período de 2013 a 2016 apresentado por Goh et al. (2016), Leonidou et al. (2017) relata que o conhecimento do consumidor em relação a iniciativas verdes das organizações está se propagando e tendo uma ascensão. Outro estudo de revisão de literatura nas mídias sociais indicou que a preocupação ambiental dos consumidores (CE), o conhecimento ambiental e o envolvimento ambiental está correlacionado ao comportamento de compra verde (GOH et al., 2016; WEl et al., 2017).

Outro fator que foi analisado foi o fator crenças (CR) com médias de 3,69, $\pm 1,00$ (escala de 1-5). Podese dizer que este fator indica as crenças gerais que a população adquire com o ambiente natural e estão relacionadas com o comportamento de compra dos consumidores. Uma pesquisa desenvolvida, realizada e administrada no Egito com uma amostra de 1093 consumidores investigou a influência de vários fatores atitudinais e psicográficos no comportamento de compra verde dos consumidores e apresentou que a atitude ambiental dos consumidores junto as suas crenças afetivas e cognitivas em relação aos serviços verdes são fatores importantes que influenciam a tomada de decisão dos consumidores sobre os comportamentos de compra verde (MOSTAFA, 2006; ZAREI et al., 2017). Essa característica de tomadores de 
decisões fundamentados e motivados pelo sustentável, indica o desenvolvimento de um perfil de consumidor mais ecológico e consciente do que antes (DEWALD et al., 2014).

O fator Atitude Local (AL) também apresentou média alta de concordância $(4,21 \pm 0,84)$, representando na escala NEP uma tendência pró-ambiental mais forte. Um estudo realizado com 3.231 alunos da Faculdade de Engenharia de uma universidade chilena com objetivo de identificar se existem diferenças no comportamento pró-ambiental entre universitários, dependendo de seu diploma de especialização (ambiental ou não), mostra que a consciência ambiental, o desenvolvimento de comportamentos ambientalmente conscientes e a formação positiva de sistemas de valores, atitudes e pensamentos, bem como o enriquecimento do conhecimento em relação ao meio ambiente e a sociedade, possibilitam ações de atitude locais e pró-ambiental (THIENGKAMOL, 2011; HEYL et al., 2013).

Este estudo indicou também que a educação em pró de um sistema ecológico constrói cidadãos bem informados e ativos; com atitudes, hábitos, valores e competências adequadas para implementar a mudança ambiental. De acordo com um estudo realizado com os estudantes universitários húngaros, o elemento mais importante na formação da consciência ambiental é a motivação individual, e a educação, indicando que a maioria dos estudantes acredita que a educação ambiental fortalece as atitudes positivas em relação ao meio ambiente (ZSÓKA et al., 2013).

Outro autor mostrou que a formação da consciência ambiental pode ser realizada de maneira institucional e organizada dentro do sistema educacional, bem como fora da instituição (HEYL et al., 2013). A contribuição familiar e de amigos foi abordada em uma pesquisa que demonstrou que eles podem impactar e serem um influenciador, bem como os meios de comunicação (televisão e a internet) que ampliam o conhecimento sobre a temática ambiental (VICENTE-MOLINA et al., 2013)

Em relação ao fator Decrescimento $(\mathrm{DC})$ obteve-se a média de $3,81( \pm 0,81)$ mostrando que os clientes se preocupam razoavelmente com o esgotamento do sistema econômico produtivo crescente a qualquer preço, que extrai demasiadamente os recursos e gera grandes quantidades de resíduos. Dessa maneira, analisando as afirmativas do fator DC pode-se inferir que os clientes simpatizam com modelos produtivos mais verdes e circulares que permitiram aos países reduzirem os danos ao meio ambiente e fechar o ciclo de vida dos produtos. Ressalta-se que o decrescimento deve ser diferenciado de uma recessão ou depressão econômica caracterizada por levar a um agravamento das condições sociais.

O decrescimento, ao contrário destas, leva a melhoria da qualidade de vida mediante a produção e consumo sustentável (SCHNEIDERA et al., 2010). Outro estudo aplicado na Ibéria e na América Latina, com estudantes universitários, encontrou um fator DC de 3,12, mostrando que os estudantes eram mais favoráveis ao crescimento econômico que os clientes do presente trabalho (CÔRTES et al., 2013).

O fator Antropocentrismo (AT) caracterizou-se como o fator com menor pontuação média de concordância $(2,29 \pm 0,97)$. No estudo de Côrtes e Moretti (2013) a média para o fator AT foi ainda mais inferior $(1,75)$ ao encontrado. Os valores elevados para esse fator indicam uma visão mais utilitária da natureza. Um estudo relevante realizado por Arne (1973) já destacava que a visão antropocêntrica é considerada como a principal causa de crise ecológica. 
A última avaliação realizada pelo fator Controle do Crescimento Econômico (CE), que tem apenas uma questão explícita na assertiva ('Para manter um meio ambiente saudável teremos que controlar o crescimento econômico') obteve uma média de concordância de 3,82. O estudo de Côrtes e Moretti (2013) apresentou um resultado inferior 2,88 mostra que o atual trabalho apresenta uma tendência favorável ao CE.

As Nações Unidas estimam que até 2050 a população mundial chegará a 9,7 bilhões, com quase 3 bilhões de pessoas a mais para alimentar (ONU, 2017). Um estudo com estudantes universitários do Brasil e de Portugal averiguou o comportamento ambiental desses estudantes, sendo que os resultados obtidos pelos dois grupos indicam que o consumo verde ainda não é tão proeminente nos dois grupos (AMÉRICO et al., 2017). Outra pesquisa com alunos de administração em São Paulo mostrou que 41\% 'não lembram' de terem comprado produtos motivados pelas ações de Responsabilidade Social e 31\% dos entrevistados enxergam as ações como uma maneira que as empresas utilizam para 'melhorar a imagem no mercado', por outro lado e 18\% "não" adquiriram produtos motivados por tais ações (TAMASHIRO et al., 2013).

\section{Propostas de gestão ambiental}

A proposta de gestão sustentável foi desenvolvida com as ferramentas de sensibilização, educação ambiental e de marketing verde, englobando todos os envolvidos, no Restaurante-Escola, como: gerência, chefe de cozinha, colaboradores e clientes, mediante aplicação das ferramentas. O processo gerencial proposto foi desenvolvido em etapas: gestão ambiental; sensibilização ambiental; educação ambiental; e marketing verde (figura 2).

As propostas de gestão ambiental desenvolvidas (figura 2) devem envolver todo o processo da organização, atendendo os objetivos de gestão e finanças da empresa alinhado ao desempenho socioambiental sustentável conforme relatado na literatura. Com o propósito de compreender e de entender o desenvolvimento sustentável da organização estudada buscou-se para a gestão ambiental o equilíbrio entre o que é socialmente desejável, economicamente viável e ambientalmente sustentável (SAVITZ et al., 2007). A gestão ambiental englobará o planejamento, organização e ensinará a empresa a atingir as metas ambientais especificas (LIMA et al., 2015).

O gestor desenvolverá a cultura interna para transmitir um conjunto de valores que orientarão a todos na empresa (GEELS et al., 2015). Serão trabalhadas as seguintes temáticas: Discutir e implantar conceitos e competências no desenvolvimento de pessoas contribuindo com o desenvolvimento sustentável e gestão por competência, que converge diretamente com a operacionalização no meio organizacional a longo prazo; Minimizar a produção de efluentes e resíduos, por meios de tecnologias limpas; Monitorar as operações ambientais continuamente; Analise dos custos ambientais; Priorizar à saúde e segurança dos empregados, consumidores e da comunidade; e Prevenção da poluição. 
Tabela 8: Distribuição de frequências das respostas relacionadas à percepção socioambiental dos 300 participantes da pesquisa. As questões estão divididas por bloco de acordo com os sete fatores analisados: preocupação local e global $(\mathrm{PR}) ; \mathrm{CV}=$ Consumo Verde; $\mathrm{AL}=$ Atitude Local; $\mathrm{DC}=$ Decrescimento; $\mathrm{AT}=$ Antropocentrismo; $\mathrm{CR}=\mathrm{Crenças;} \mathrm{CE}=$ Controle do Crescimento Econômico. As opções de resposta são 'Discordo totalmente', 'Discordo em parte', 'Não concordo nem discordo', 'Concordo em parte' e 'Concordo totalmente'.

\begin{tabular}{|c|c|c|c|c|c|c|c|c|}
\hline Questão n (\%) & $\begin{array}{c}\text { Fator } \\
\text { avaliado }\end{array}$ & $\begin{array}{l}\text { Discordo } \\
\text { totalmente } \\
\text { (1) }\end{array}$ & $\begin{array}{c}\text { Discordo } \\
\text { em } \\
\text { parte (2) }\end{array}$ & \begin{tabular}{|c|} 
Não \\
concordo \\
nem \\
discordo \\
$(3)$ \\
\end{tabular} & $\begin{array}{l}\text { Concordo } \\
\text { em parte } \\
\text { (4) }\end{array}$ & $\begin{array}{c}\text { Concordo } \\
\text { totalmente } \\
(5)\end{array}$ & Média por questão & $\begin{array}{l}\text { Média } \\
\text { por } \\
\text { fator } \\
( \pm S D)\end{array}$ \\
\hline $\begin{array}{l}\text { A redução do aquecimento global deve } \\
\text { receber atenção prioritária de todos os } \\
\text { países }\end{array}$ & \multirow{7}{*}{ PR } & $12(4)$ & $9(3)$ & $14(4,67)$ & $\begin{array}{c}58 \\
(19,33)\end{array}$ & $207(69)$ & 4,46 & \multirow{7}{*}{$\begin{array}{c}4,51 \\
( \pm 0,61)\end{array}$} \\
\hline $\begin{array}{l}\text { O desmatamento das grandes florestas } \\
\text { pode comprometer o futuro da } \\
\text { humanidade }\end{array}$ & & $3(1)$ & $8(2,67)$ & $4(1,33)$ & $22(7,33)$ & $263(87,67)$ & 4,78 & \\
\hline $\begin{array}{l}\text { Poluição de rios e lagos poderá afetar } \\
\text { qualidade de vida humanos }\end{array}$ & & $3(1)$ & $5(1,67)$ & $1(0,33)$ & $13(4,33)$ & $278(92,67)$ & 4,86 & \\
\hline $\begin{array}{l}\text { A poluição do ar na minha cidade é } \\
\text { algo que me preocupa muito }\end{array}$ & & $31(10,33)$ & $26(8,67)$ & $\begin{array}{c}38 \\
(12,67) \\
\end{array}$ & $\begin{array}{ll}106 \\
(35,33)\end{array}$ & $99(33)$ & 3,72 & \\
\hline $\begin{array}{l}\text { A destinação do lixo urbano deve } \\
\text { receber atenção permanente dos } \\
\text { administradores públicos }\end{array}$ & & $5(1,67)$ & $3(1)$ & $15(5)$ & $\begin{array}{c}50 \\
(16,67)\end{array}$ & $227(75,67)$ & 4,64 & \\
\hline $\begin{array}{l}\text { A poluição dos oceanos deve merecer } \\
\text { uma atenção prioritária de todos os } \\
\text { países }\end{array}$ & & $5(1,67)$ & $10(3,33)$ & $10(3,33)$ & $60(20)$ & $215(71,67)$ & 4,57 & \\
\hline $\begin{array}{l}\text { As empresas devem ser incentivadas a } \\
\text { utilizar matéria prima reciclada como } \\
\text { uma forma de reduzir o seu impacto } \\
\text { ambiental }\end{array}$ & & $5(1,67)$ & $6(2)$ & $20(6,67)$ & $\begin{array}{c}49 \\
(16,33)\end{array}$ & $220(73,33)$ & 4,58 & \\
\hline $\begin{array}{l}\text { A facilidade de descarte ou reciclagem } \\
\text { deve sempre ser considerada no } \\
\text { momento da compra de um produto }\end{array}$ & \multirow{6}{*}{$\mathrm{CV}$} & $12(4)$ & $18(6)$ & $\begin{array}{c}44 \\
(14,67)\end{array}$ & $72(24)$ & $154(51,33)$ & 4,13 & \multirow{6}{*}{$\begin{array}{c}3,56 \\
( \pm 0,87)\end{array}$} \\
\hline $\begin{array}{l}\text { Um certificado que indique, que um } \\
\text { produto foi feito seguindo normas } \\
\text { ambientais, auxilia na minha decisão } \\
\text { de compra }\end{array}$ & & $22(7,33)$ & $17(5,67)$ & $\begin{array}{c}44 \\
(14,67)\end{array}$ & $\begin{array}{c}85 \\
(28,33)\end{array}$ & $132(44)$ & 3,96 & \\
\hline $\begin{array}{l}\text { Quando compro, dou prioridade a } \\
\text { produtos que sejam mais facilmente } \\
\text { recicláveis }\end{array}$ & & $27(9)$ & $\begin{array}{c}35 \\
(11,67)\end{array}$ & $\begin{array}{c}95 \\
(31,67)\end{array}$ & $\begin{array}{c}80 \\
(26,67)\end{array}$ & $63(21)$ & 3,39 & \\
\hline $\begin{array}{l}\text { Na escolha de um produto, dou } \\
\text { prioridade mais a aspectos ambientais } \\
\text { do que ao preço / qualidade }\end{array}$ & & $57(19)$ & $\begin{array}{c}73 \\
(24,33)\end{array}$ & $78(26)$ & $\begin{array}{c}65 \\
(21,67)\end{array}$ & 27 (9) & 2,77 & \\
\hline $\begin{array}{l}\text { Entre dois produtos similares, eu daria } \\
\text { preferência àquele que foi produzido } \\
\text { com matéria prima reciclada }\end{array}$ & & $20(6,67)$ & $28(9,33)$ & $\begin{array}{c}74 \\
(24,67)\end{array}$ & $78(26)$ & $100(33,33)$ & 3,70 & \\
\hline $\begin{array}{l}\text { Eu adquiro produtos que não } \\
\text { desperdiçam recursos em suas } \\
\text { embalagens }\end{array}$ & & $29(9,67)$ & $\begin{array}{c}35 \\
(11,67)\end{array}$ & $\begin{array}{c}88 \\
(29,33)\end{array}$ & $\begin{array}{c}73 \\
(24,33)\end{array}$ & $75(25)$ & 3,43 & \\
\hline $\begin{array}{l}\text { Eu devo economizar energia elétrica } \\
\text { na minha casa para contribuir para a } \\
\text { melhoria do meio ambiente }\end{array}$ & \multirow{3}{*}{ AL } & $8(2,67)$ & $13(4,33)$ & $14(4,67)$ & $51(17)$ & $214(71,33)$ & 4,50 & \multirow{3}{*}{$\begin{array}{c}4,21 \\
( \pm 0,84)\end{array}$} \\
\hline $\begin{array}{l}\text { Devo utilizar o transporte público para } \\
\text { ajudar o meio ambiente }\end{array}$ & & $26(8,67)$ & $\begin{array}{c}37 \\
(12,33) \\
\end{array}$ & $51(17)$ & $\begin{array}{c}82 \\
(27,33) \\
\end{array}$ & $104(34,67)$ & 3,67 & \\
\hline $\begin{array}{l}\text { Tenho que economizar água em casa } \\
\text { para cuidar do meio ambiente }\end{array}$ & & $7(2,33)$ & $16(5,33)$ & $8(2,67)$ & $51(17)$ & $218(72,67)$ & 4,52 & \\
\hline $\begin{array}{l}\text { O crescimento urbano é cada vez mais } \\
\text { prejudicial ao ambiente }\end{array}$ & \multirow{4}{*}{ DC } & $9(3)$ & $16(5,33)$ & $42(14)$ & $111(37)$ & $122(40,67)$ & 4,07 & \multirow{4}{*}{$\begin{array}{c}3,81 \\
( \pm 0,81)\end{array}$} \\
\hline $\begin{array}{l}\text { Sou favorável a um imposto } \\
\text { internacional para os países que geram } \\
\text { mais gases de efeito estufa }\end{array}$ & & $24(8)$ & $13(4,33)$ & $\begin{array}{c}59 \\
(19,67)\end{array}$ & $\begin{array}{c}79 \\
(26,33)\end{array}$ & $125(41,67)$ & 3,89 & \\
\hline $\begin{array}{l}\text { Alguns países devem ter o seu } \\
\text { crescimento econômico limitado para } \\
\text { evitar o uso abusivo de recursos } \\
\text { naturais }\end{array}$ & & $36(12)$ & $36(12)$ & $\begin{array}{c}71 \\
(23,67)\end{array}$ & $\begin{array}{c}80 \\
(26,67)\end{array}$ & $77(25,67)$ & 3,42 & \\
\hline $\begin{array}{l}\text { A durabilidade de um produto reduz } \\
\text { seu impacto ambiental, mesmo que } \\
\text { ele custe mais caro }\end{array}$ & & $16(5,33)$ & $19(6,33)$ & $\begin{array}{c}68 \\
(22,67)\end{array}$ & $\begin{array}{c}89 \\
(29,67)\end{array}$ & $108(36)$ & 3,85 & \\
\hline $\begin{array}{l}\text { Os seres humanos têm o direito de } \\
\text { modificar o ambiente natural para } \\
\text { atender às suas necessidades }\end{array}$ & \multirow[t]{2}{*}{ AT } & $82(27,33)$ & $\begin{array}{c}92 \\
(30,67)\end{array}$ & $19(6,33)$ & $84(28)$ & $23(7,67)$ & 2,58 & \multirow[t]{2}{*}{$\begin{array}{c}2,29 \\
( \pm 0,97)\end{array}$} \\
\hline $\begin{array}{l}\text { A humanidade foi criada para governar } \\
\text { o resto da natureza }\end{array}$ & & $135(45)$ & $63(21)$ & $33(11)$ & $\begin{array}{c}49 \\
(16,33)\end{array}$ & $20(6,67)$ & 2,19 & \\
\hline
\end{tabular}




\begin{tabular}{|c|c|c|c|c|c|c|c|c|}
\hline $\begin{array}{l}\text { A humanidade não precisa se adaptar } \\
\text { ao ambiente natural porque pode } \\
\text { modificá-lo para atender suas } \\
\text { necessidades }\end{array}$ & & $126(42)$ & $90(30)$ & $26(8,67)$ & $42(14)$ & $16(5,33)$ & 2,11 & \\
\hline $\begin{array}{l}\text { Estamos nos aproximando do número } \\
\text { máximo de pessoas que a Terra pode } \\
\text { suportar }\end{array}$ & \multirow[b]{3}{*}{ CR } & $52(17,33)$ & $\begin{array}{c}37 \\
(12,33)\end{array}$ & $\begin{array}{c}46 \\
(15,33)\end{array}$ & $\begin{array}{c}115 \\
(38,33)\end{array}$ & $47(15,67)$ & 3,20 & \multirow{3}{*}{$\begin{array}{c}3,69 \\
( \pm 1,00)\end{array}$} \\
\hline $\begin{array}{l}\text { O equilíbrio da natureza é muito } \\
\text { delicado e facilmente perturbado }\end{array}$ & & $12(4)$ & $30(10)$ & $16(5,33)$ & $\begin{array}{c}83 \\
(27,67) \\
\end{array}$ & $159(53)$ & 4,16 & \\
\hline $\begin{array}{l}\text { Para manter um meio ambiente } \\
\text { saudável, teremos que controlar o } \\
\text { crescimento econômico }\end{array}$ & & $19(6,33)$ & $39(13)$ & $26(8,67)$ & $\begin{array}{c}110 \\
(36,67)\end{array}$ & $106(35,33)$ & 3,82 & \\
\hline $\begin{array}{l}\text { Média geral da percepção } \\
\text { socioambiental }\end{array}$ & & & & & & & & $\begin{array}{c}3,97 \\
( \pm 0,58)\end{array}$ \\
\hline
\end{tabular}

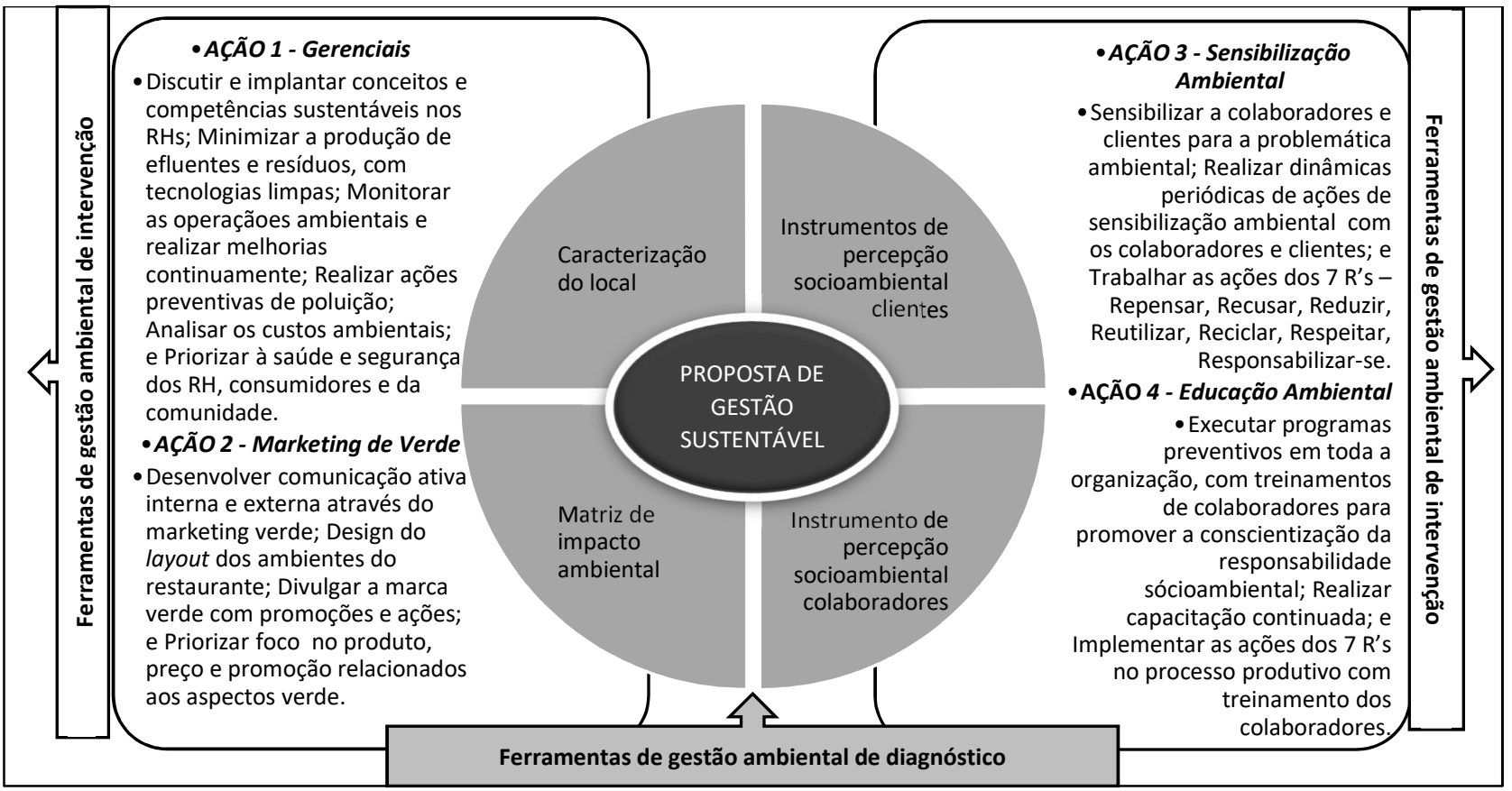

Figura 2: Progressão cíclica da proposta de gestão sustentável do restaurante. O primeiro nível representa as

ferramentas de gestão ambiental de diagnóstico exibidas na cor cinza em quatro itens no formato de cunha. O segundo nível representa as ferramentas de gestão ambiental de intervenção: 4 ações dispostas nos dois retângulos na lateral do primeiro nível.

Posteriormente a proposta gerencial inicial, serão desenvolvidas as ações da sensibilização ambiental. As ações de sensibilização são mais breves e intensas que por si só não levarão a mudanças duradouras, e sim será uma preparação para as ações de educação ambiental. Estas propostas de sensibilização incluirão: sensibilizar a funcionários e clientes para a problemática ambiental; realizou encontros com dinâmicas periódicos com os funcionários e clientes, envolvendo a todos através de ações de sensibilização ambiental; e ações de Reciclagem 3 Rs - Reduzir, Reciclar, Reutilizar.

Dentro da demanda organizacional, a educação ambiental é uma ferramenta proposta para ser utilizada no processo de gestão (figura 2) como forma de repensar as ações e relações com o meio que vivemos sendo uma práxis educativa e social, bem como um instrumento de transformação social para um desenvolvimento (LOUREIRO et al., 2011). Estudos indicam que a melhor compreensão da temática ajuda a entender os desafios ecológicos e a visão empresarial como gerentes e planejadores orientando seus valores e comportamentos para um relacionamento harmonioso com a natureza e promove o desafio social que impulsiona a transformar radicalmente as estruturas de gestão (NOVO, 2009; ZSÓKA et al., 2013). 
As pospostas de Educação Ambiental incluíram: Programas preventivos que se estende por toda a organização; Treinamentos de funcionários promovendo a conscientização e responsabilidade sócio ambiental; Capacitação continua; Influência da política ambiental nos processos; e Redução, recuperação de produtos e embalagens após o uso, para reuso e reciclagem. De fato, a empresa expor seus valores ecológicos para seus colaboradores se torna tão importante quanto o marketing de sua missão para os consumidores (WELLS et al., 2015). Portanto, os valores ambientais precisam ser compartilhados e comunicados entre os departamentos. Transmitir o conhecimento através da educação ambiental ajuda a incorporar uma cultura ambiental em toda a organização e desenvolve habilidades nos funcionários para aplicar estratégias ambientais bem-sucedidas (MCDONAGH et al., 2014).

No processo gerencial encontra-se a ferramenta de marketing verde que faz comunicação de todo o processo até o consumidor. Os gestores identificam a importância de promover o marketing verde em toda a organização, construindo assim a sustentabilidade no desempenho de suas pessoas, produtos e serviços (UNRUH et al., 2010).

A propostas de marketing verde incluíra: Desenvolver comunicação ativa interna e externa através do marketing verde; Design do layout dos ambientes do restaurante; Divulgação da marca verde através de promoções e ações enfatizando o produto, serviço e a empresa verde; Visão estratégica verde a longo prazo, se diferenciando e se destacando no mercado; e Foco no produto, preço e promoção relacionados aos aspectos verdes. Dessa forma, o diálogo interno com o marketing verde envolve a concepção de valores ambientais em toda a organização para incorporar uma cultura verde corporativa mais ampla (PAPADAS et al., 2014).

Para finalizar o processo sustentável mapearam-se os pontos de intervenção para a aplicação das ferramentas de gestão ambiental: sensibilização ambiental, educação ambiental e de marketing verde. Os pontos de intervenções foram detectados pelo diagnóstico do processo produtivo (caracterização do local de estudo e diagnóstico do impacto ambiental) e pelo diagnóstico da percepção ambiental dos colaboradores e clientes.

Dessa maneira, chegaram-se as seguintes necessidades de intervenção: as relacionadas ao processo produtivo (produção/armazenamento embalagem, nas dimensões gerência, chefe de cozinha, colaboradores; escolha do cardápio nas dimensões gerência, chefe de cozinha); e as relacionadas ao consumo e o descarte (Consumo, Desperdício; Embalagens e Materiais Descartáveis Descarte, ambas nas dimensões gerência, chefe de cozinha, colaboradores e clientes) (figura 3). 


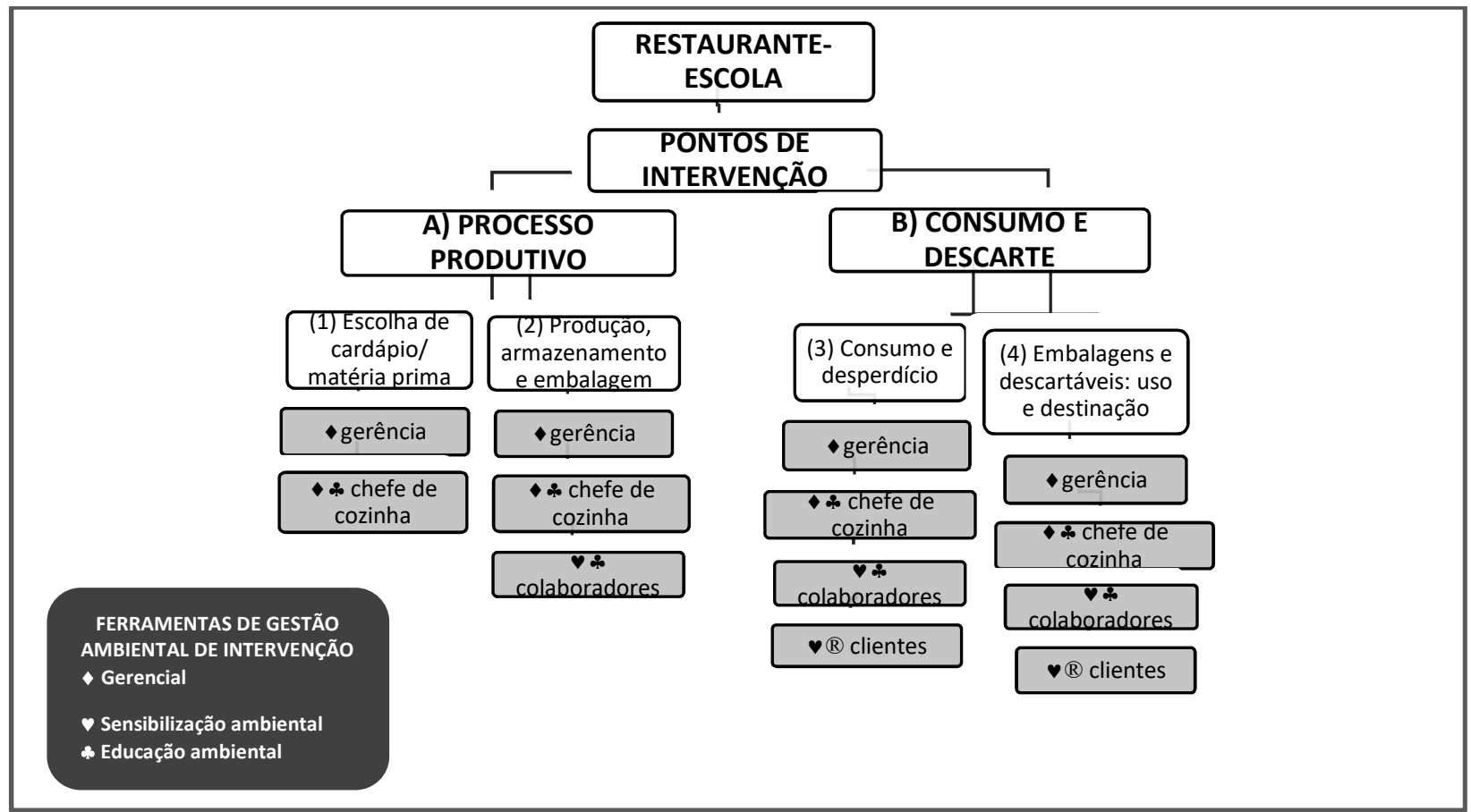

Figura 3: Mapa dos pontos de intervenção para a aplicação das ferramentas de gestão ambiental de intervenção. A) intervenções relacionadas ao processo produtivo: (1) escolha de cardápio e das matérias primas e (2) produção, armazenamento e embalagem. (B) intervenções relacionadas ao consumo e descarte: (3) consumo e desperdício e (4) embalagens, descartáveis e destinação final. Retângulos cinzas indicam as dimensões envolvidas para se fazer as intervenções, em ordem hierárquica: gerência, chefe de cozinha, colaboradores e clientes. A legenda das ferramentas de intervenção está exibida no retângulo cinza a esquerda.

\section{CONCLUSÃO}

Os colaboradores apresentam níveis medianos de conhecimento socioambiental e de planejamento de vida; quanto ao comportamento ecológico os níveis apresentados foram modestos, porém, os indivíduos pesquisados evidenciaram grande preocupação com o comportamento social. Nos clientes, a percepção socioambiental indicou, na maioria dos fatores avaliados (PR, AL, DC, AT, CR, CE), uma concordância para as questões positivas relacionadas a temática socioambiental como um todo, e em particular no fator antropocentrismo, a discordância, o que é positivo para eficiência do instrumento.

Por outro lado, nas questões que compunham o fator consumo verde, obteve-se que a maioria dos clientes não praticavam os hábitos verdes, ou eram indiferentes a eles, indicando que mesmo tendo entendimento sobre as questões socioambientais avaliadas nos fatores comportamentos PR, AL, DC, AT, CR, CE; o participante não colocava frequentemente em seu consumo a prática de hábitos e compras verdes. A interpretação do diagnóstico de percepção mostrou que tanto os colaboradores e os clientes possuem um mediano conhecimento pró-social e pró-ambiental, no entanto carecem de colocar em prática estes comportamentos.

Baseado nestes resultados, detectou-se uma necessidade imediata de inserção de instrumentos de educação ambiental e ações de marketing verde no grupo estudado, principalmente por se tratar de um restaurante inserido dentro de um contexto universitário, ou seja, pedagógico. Além disso, a aplicação do questionário de percepção socioambiental possibilitou compreender a importância da educação ambiental no contexto empresarial e pedagógico, assim como, diagnosticar que os colaboradores e clientes envolvidos 
no processo necessitam adotar um comportamento mais sustentável, visto que influenciam diretamente a construção sustentável da organização.

O desenvolvimento da presente proposta de gestão ambiental, juntamente com os diagnósticos efetuados indicam que o processo gerencial deve passar por um período de transição e de implementação de ações sustentáveis, pois estão desafiados a encontrar novas formas e práticas produtivas sustentáveis. Para isso, foi possível entender o conhecimento ambiental dos colaboradores e clientes.

A proposta do estudo obteve sucesso em analisar a percepção socioambiental dos colaboradores e clientes do restaurante escola e no desenvolvimento das ações de práticas sustentáveis estratégias de educação ambiental e marketing verde inserindo-as na gestão ambiental. Isso indica que a metodologia de diagnóstica (matriz de impacto e instrumentos de percepção socioambiental) utilizada foi eficiente para conduzir o desenvolvimento da proposta de ação.

\section{REFERÊNCIAS}

AKENJI, L.. Consumer scapegoatism and limits to green consumerism. Journal of Cleaner Production, v.63, p.13-23, 2014. DOI: https://doi.org/10.1016/j.jclepro.2013.05.022

ALCÂNTARA, L. A.; SILVA, M. C. A.; NISHIJIMA, T.. Educação ambiental e os sistemas de gestão ambiental no desafio do desenvolvimento sustentável. REGET, v.5, n.5, p.734-740, 2012. DOI: http://doi.org/10.5902/223611704198

ALMEIDA, D. M.; MADRUGA, L. R. R. G.; LOPES, L. F. D.; IBDAIWI, T. K. R.. Comportamento ecológico de alunos pósgraduandos de uma instituição pública. Desenvolvimento em Questão, v.13, n.29, p.289-310, 2015. DOI: https://doi.org/10.21527/2237-6453.2015.29.289-310

ALVES, I. J. B. R.; FREITAS, L. S.. Análise comparativa das ferramentas de gestão ambiental: produção mais limpa $x$ ecodesign. In: LIRA, W. S.; CÂNDIDO, G. A.. Gestão sustentável dos recursos naturais: uma abordagem participativa. Campina Grande: EDUEPB, 2013. p.193-212.

AMARAL, L.. Alimentação fora do lar movimenta bilhões de reais. Belo Horizonte: ABRASEL, 2017.

AMÉRIGO, M.; GARCIA, J. A.; CORTES, P. L.. Análise das atitudes e comportamentos pró-ambientais: um estudo exploratório com uma amostra de estudantes universitários brasileiros. Ambiente \& Sociedade, São Paulo, v.20, n.3, p.120, 2017. DOI: http://doi.org/10.1590/18094422asoc300r1v2032017

ARAÚJO, E. L. M.; CARVALHO, A. C. M. S.. Sustentabilidade e geração de resíduos em uma unidade de alimentação e nutrição da cidade de Goiânia-GO. Demetra, Rio de Janeiro, v.10, n.4, p.775-796, 2015. DOI:

https://doi.org/10.12957/demetra.2015.17035

ARNE, N.. O movimento ecológico superficial e de longo alcance. Inquérito, v.16, p.95-100, 1973.

AXON, S.. Keeping the ball rolling: Addressing the enablers of, and barriers to, sustainable lifestyles. Journal of Environmental Psychology, v.52, p.11-25, 2017. DOI: https://doi.org/10.1016/j.jenvp.2017.05.002
BARBIERI, J. C.; CAJAZEIRA, J. E. R.. Responsabilidade social empresarial e empresa sustentável: da teoria à prática. São Paulo: Saraiva, 2009.

BEURON, T. A.; SCHUCH JÚNIOR, V. F.; MADRUGA, L. R. R. G.; CARPES, A. M.. Relações entre os valores pessoais e os comportamentos ecológicos no contexto da sustentabilidade. Revista Ibero-Americana de Ciências Ambientais, Aquidabã, v.3, n.2, p.6-22, 2012.

BRASIL. Lei n.12305 de 02 de agosto de 2010. Institui a Política Nacional de Resíduos Sólidos; altera a Lei no 9.605, de 12 de fevereiro de 1998; e dá outras providências. Brasília: DOU, 2010.

CHAMBERS, D.; ROBERTS, S.; LEWIS-CAMERON, A.. Papers from Conference Proceedings of the 1st International Tourism Conference - 'Beyond the boundary: Creating new epistemologies in tourism'. Tourism and Hospitality Research, v.10, n.4, 2010, p.286-300. DOI: http://doi.org/10.1057/thr.2010.8

CÔRTES, P.; MORETTI, S. L. A.. Consumo Verde: um estudo transcultural sobre crenças, preocupações e atitudes ambientais. Revista Brasileira de Marketing, v.12, n.3, 2013. DOI: http://doi.org10.5585/remark.v12i3.2592

DAHLSTROM, R.. Green marketing management. Masom: Southwestern University, 2011.

DEWALD, B.; BRUIN, B. J.; JANG, Y. J.. US consumer attitudes towards "green" restaurants. International Journal of Tourism and Hospitality Research v.25, p.171-180, 2014. DOI: http://doi.org/10.1080/13032917.2013.839457

DOSZHANOV, A.; AHMAD, Z. A.. Customers' intention to use green products: The impact of green brand dimensions and green perceived value. In: SHS Web of Conferences, v.18, 2015. DOI: http://doi.org10.1051/shsconf/20151801008

DUNLAP, R. E.; LIERE, K. D.; MERTIG, A. G.; EMMET JONES, R.. Measuring endorsement of the new ecological paradigm: 
a revised NEP scale. Journal of Social Issues, v.56, n.3, p.425442, 2000. DOI: http://dx.doi.org/10.1111/0022-4537.00176

DUNLAP, R. E.; LIERE, K.. The New Environmental Paradigm. The Journal of Environmental Education, v.9, p.10-19, 1978. DOI: https://doi.org/10.1080/00958964.1978.10801875

ENGERT, S.; RAUTER, R.; BAUMGARTNER, R. J.. Exploring the integration of corporate sustainability into strategic management: a literature review. Journal of Cleaner

Production v.112, p.2833-2850, 2016. DOI:

https://doi.org/10.1016/j.jclepro.2015.08.031

EOM, K.; KIM, H. S.; SHERMAN, D. K.; ISHII, K.. Cultural variability in the link between environmental concern and support for environmental action. Psychological Science, v.27, p.1331-1339, 2016. DOI: https://doi.org/10.1177/0956797616660078

FIELD, A.. Discovering statistics using IBM SPSS Statistics. 4 ed. London: Sage, 2013.

FINNEY, S. L.. Encouraging sustainable consumption: An exploration of consumer behavior. The Marketing Review, v.14, n.2, p.189-203, 2014. DOI:

https://doi.org/10.1362/146934714X14024778816959

FLEMING, A.; WISE, R. M.; HANSEN, H.; SAMS, L.. The sustainable development goals: a case study. Marine Policy, v.86, p.94-103, 2017, DOI:

https://doi.org/10.1016/j.marpol.2017.09.019

FLEMING, J. G. B.; BATTI, L. S. Z.. Importância da prática de hábitos positivos praticados pelos líderes para o sucesso da organização. Iniciação Científica, Criciúma, v.15, n.2, 2017.

GEELS, F. W.; MCMEEKIN, A.; MYLAN, J.; SOUTHERTON, D.. A critical appraisal of Sustainable Consumption and Production research: The reformist, revolutionary and reconfiguration positions. Global Environmental Change, v.34, p.1-12, 2015. DOI: https://doi.org/10.1016/i.gloenvcha.2015.04.013

GOH, S. K.; BALAJI, M. S.. Linking green skepticism to green purchase behavior. Journal of Clean Production, v.131, p.629-638, 2016. DOI:

https://doi.org/10.1016/j.jclepro.2016.04.122

GORNI, P. M.; GOMES, G.; DREHER, M. T.. Consciência ambiental e gênero: os universitários e o consumo sustentável. In: SIMPÓSIO DE ADMINISTRAÇÃO DA PRODUÇÃO, LOGÍSTICA E OPERAÇÕES INTERNACIONAIS, 14. Anais. São Paulo: FGV, 2011.

GOUVEIA, V. V.; CLEMENTE, M.. La medida del individualismo y del colectivismo: La investigación en el campo de la Psicología Cultural. La Coruña: EDULC, 1998.

HAHN, T.; SCHEERMESSER, M.. Approaches to corporate sustainability among German companies. Corporate Social Responsibility and Environmental Management, v.13, n.3, p.150-165, 2006. DOI: https://doi.org/10.1002/csr.100

HALL, C. M.. Framing behavioural approaches to understanding and governing sustainable tourism consumption: Beyond neoliberalism, "nudging" and "green growth"?. Journal of Sustainable Tourism, v.21, p.1091-110, 2013. DOI: https://doi.org/10.1080/09669582.2013.815764
HAN, H.. Travelers' pro-environmental behavior in a green lodging context: converging value-belief-norm theory and the theory of planned behavior. Tourism Manage, v.47, p.164-177, 2015. DOI: https://doi.org/10.1016/j.tourman.2014.09.014

HAN, H.; HSU, L.; SHEU, C.. Application of the theory of planned behavior to green hotel choice: testing the effect of environmentally friendly activities. Tourism Manage, v.31, p.325-334, 2010. DOI: https://doi.org/10.1016/j.tourman.2009.03.013

HAN, H.; HWANG, J.; KIM, J.; JUNG, H.. Guests' proenvironmental decision-making process: broadening the norm activation framework in a lodging context.

International Journal of Hospitality Management, v.47, p.96-107, 2015. DOI:

https://doi.org/10.1016/j.ijhm.2015.03.013

HEYL, M.; MOYANO DÍAZ, Y, E.; CIFUENTES, L..

Environmental attitudes and behaviors of college students: a case study conducted at a Chilean university. Revista LatinoAmericana de Psicologia, v.45, p.489-502, 2013. DOI: http://dx.doi.org/10.14349/rlp.v45i3.1489

HOUSE, R.; HANGES, P.; JAVIDAN, M.; DORFMAN P.; GUPTA, V.. Leadership, Culture, and Organizations: The GLOBE Study of 62 Societies. Beverly Hills: Sage, 2004.

HU, H. H.; PARSA, H. G.; JOHN, S.. The Dynamics of green restaurant patronage. New York: Cornell Hospital, 2010.

HU, M.; HORNG, J. S.; TENG, C. C.; CHOU, S. F.. A criteria model of restaurant energy conservation and carbon reduction in Taiwan. Journal of Sustainable Tourism, v.21, p.765-779, 2013. DOI: https://doi.org/10.1080/09669582.2012.721787

KAUFMANN, H. R.; PANNI, M. F. A. K.; ORPHANIDOU, Y.. Factors affecting consumers' green purchasing behaviour: an integrated conceptual framework. Amfiteatru Economic, v.14, n.31, p.50-69, 2012.

KIRSCHBAUM, C.. Decisões entre pesquisas quali e quanti sob a perspectiva de mecanismos causais. Revista Brasileira de Ciências Sociais, São Paulo, v.28, n.82, p.179-193, 2013. DOI: http://dx.doi.org/10.1590/S0102-69092013000200011

KWOK, L.; HUANG, Y.; HU, L.. Green attributes of restaurants: what really matters to consumers?. International Journal of Hospitality Management, v.55, p.107-117, 2016. DOI: https://doi.org/10.1016/j.ijhm.2016.03.002

LAMIM-GUEDES, V.. Pegada de Carbono: práticas educativas sobre mudanças climáticas. Educação Ambiental em Ação, v.44, n.12, 2013.

LEFF, E.. Saber Ambiental: Sustentabilidade, Racionalidade, Complexidade, Poder. Petrópolis: Vozes, 2001.

LEONIDOU, C. N.; SKARMEAS, D.. Gray shades of green: causes and consequences of green skepticism. Journal of Business Ethics, v.144, p.401-415, 2017. DOI: https://doi.org/10.1007/s10551-015-2829-4 
LEOPOLD, L. B.; CLARKE, F. E. C.; HANSHAW, B. B.; BALSLEY, J. R.. A procedure for evaluating environmental impact. Washington: U. S. Geological Survey, 1971.

LIMA, G. B.; LIBONI, L. B.; GOMES, A. F.; CARVALHO, D. T.. Marketing verde e gestão ambiental nas organizações: um estudo teórico-conceitual. FACEF Pesquisa:

Desenvolvimento e Gestão, v.18, n.1, p.67-81, 2015.

LIRA, W. S.; CÂNDIDO, G. A.. Gestão sustentável dos recursos naturais: uma abordagem participativa. Campina Grande: EDUEPB, 2013.

LOUREIRO, C. F. B.; LAYRARGUES, P. P.; CASTRO, R. S. Educação ambiental: repensando o espaço da cidadania. 5 ed. São Paulo: Cortez, 2011.

MANIATIS, P.. Investigating factors influencing consumer decision-making while choosing green products. Journal of Cleaner Production, v. 132, p. 215-228, 2015. DOI: https://doi.org/10.1016/j.jclepro.2015.02.067

MORIN, E.. Educação e complexidade: os sete saberes necessários à educação do futuro. São Paulo: Cortez, 2002.

MOSTAFA, M. M.. Antecedents of Egyptian consumers green purchase intentions. Journal of Consumer Marketing, v.19, p.97-126, 2006. DOI:

https://doi.org/10.1300/J046v19n02 06

NAMKUNG, Y.; JANG, S.. Effects of restaurant green practices on brand equity formation: do green practices really matter?. International Journal of Hospitality Management, v.33, p.85-95, 2013. DOI:

https://doi.org/10.1016/j.ijhm.2012.06.006

NOVO, M.. Educação ambiental, uma educação genuína para o desenvolvimento sustentável. Revista Eletrônica de Educação, p.195-217, 2009.

ONU. United Nations. World Population Prospects: the 2017: Revision. New York: 2017.

PAPADAS, K. K.; AVLONITIS, G. J.. The 4 C's of environmental business: introducing a new conceptual framework. Social Business, v.4, n.4, p.345-360, 2014. DOI: https://doi.org/10.1362/204440814X14185703122928

PARK, J.; KIM, H. J.. Environmental proactivity of hotel operations: antecedents and the moderating effect of ownership type. International Journal of Hospitality Management, v.37, p.1-10, 2014. DOI: https://doi.org/10.1016/j.ijhm.2013.09.011

PARK, J.; KIM, H. J.; MCCLEARY, K. W.. The impact of top management's environmental attitudes on hotel companies' environmental management. Journal of Hospitality \& Tourism Research, v.38, n.1, p.95-115, 2014. DOI: http://doi.org/10.1177/1096348012452666

PATO, C. M. L.; TAMAYO, Á.. A Escala de Comportamento Ecológico: desenvolvimento e validação de um instrumento de medida. Estudos Psicológicos, Natal, v.11, n.3, 2006. DOI: http://doi.org/10.1590/S1413-294X2006000300006
PATO, C.. Comportamento ecológico: relações com valores pessoais e crenças ambientais. Tese (Doutorado) Universidade de Brasília, Brasília, 2004.

POLONSKY, M. J.; VOCINO, A.; GRAU, S. L.; GARMA, R.; FERDOUS, A. S.. The impact of general and carbon related environmental knowledge on attitudes and behaviour of US consumers. Journal of Marketing Management, v.28, p.238263, 2012.

PROTHERO, A.; MCDONAGH, P.. Sustainability marketing research: Past, present and future. Journal of Marketing Management, v.30, p.1186-1219, 2014. DOI: http://doi.org/10.1080/0267257X.2014.943263

PUNTEL, L.; MARINHO, K. B.. Gastronomia e Sustentabilidade: uma análise da percepção da sustentabilidade ambiental em restaurantes buffet. Revista Turismo em Análise, v.26, n.3, p.668-694. 2015. DOI: http://doi.org/10.11606/issn.1984-4867.v26i3p668-694

QUEVEDO, V. O. R.. A Água nossa de cada dia: percepção, uso e predisposições comportamentais de alunos do ensino médio de Natal, Rio Grande do Norte. Dissertação (Mestrado em Psicologia, Sociedade e Qualidade de Vida) Universidade Federal do Rio Grande do Norte, Natal, 2005.

SARMIENTO, C. V.; HANANDEH, A. E.. Customers' perceptions and expectations of environmentally sustainable restaurant and the development of green index: The case of the Gold Coast, Australia. Sustainable Production and Consumption, v.15, p.16-24, 2018. DOI: https://doi.org/10.1016/j.spc.2018.04.001

SATO, M.; OLIVEIRA, H.; ZANON, A. M.; VARGAS, I. A.; WISIACK, S. R. C.; PEREIRA, D. M.. Processo Formativo Escolas Sustentáveis e Com-Vida. Ouro Preto: Universidade Federal de Ouro Preto, 2010

SAVITZ, A. W.; WEBER, K.. A empresa sustentável: o verdadeiro sucesso é lucro com responsabilidade social e ambiental. Rio de Janeiro: Elsevier, 2007.

SCHNEIDER, F.; KALLIS, G.; MARTINEZ-ALIER, J.. Crisis or opportunity? Economic degrowth for social equity and ecological sustainability. Introduction to this special issue. Journal of Cleaner Production v.18, p.511-518, 2010. DOI: http://doi.org/10.1016/j.jclepro.2010.01.014

SEVERO, E. A.; GUIMARÃES J. C. F.; DORION E. C.; NODARI, C. H.. Cleaner production, environmental sustainability and organizational performance: an empirical study in the Brazilian Metal-Mechanic industry. Journal of Cleaner Production, v.96, p.118-125, 2014. DOI: https://doi.org/10.1016/j.jclepro.2014.06.027

SILVA FILHO, J. C. L.; CASTRO NETO, F. C.; ABREU, M. C. S.; CANTALICE, F. L. B. M.; BARBOSA JÚNIOR, C. D. S. C.. Estudo sobre o novo paradigma ecológico (NPE) no Brasil: Medindo a consciência ambiental através da escala-nep. ENCONTRO DA ENANPAD, 34. Anais. Rio de Janeiro: ANPAD, 2010.

SILVESTRE, B. S.; SILVA NETO, R.. Are cleaner production innovations the solution for small mining operations in poor regions? The case of Padua in Brazil. Journal of Cleaner Production, v.84, p.809-817, 2014. DOI:

https://doi.org/10.1016/i.jclepro.2014.01.097 
SMITH, L.; BALL, P.. Steps towards sustainable manufacturing through modelling material, energy and waste flows.

International Journal of Production Economics, v.140, n.1, p.227-238, 2012. DOI:

https://doi.org/10.1016/j.ijpe.2012.01.036

SUKI, N. M.. Young consumer ecological behaviour: The effects of environmental knowledge, healthy food, and healthy way of life with the moderation of gender and age. Management of Environmental Quality: An International Journal, v.24, p.726-737, 2013. DOI: https://doi.org/10.1108/MEQ-02-2013-0010

TAMASHIRO, H. R. S.; MURARI, W. A.; OLIVEIRA, S. V. W. B.; ACEVEDO, C. R.. Consumer socio-environmental behavior: A study with college students in the countryside of the State of Sao Paulo. Production, v.22, n.2, p.201-212, 2013. DOI: http://doi.org/10.1590/S0103-65132012005000011

TAMBOSI, S. S. V.; MONDINI, V. E. D.; BORGES, G. R.; HEIN, N.. Consciência Ambiental, Hábitos de Consumo Sustentável e Intenção de Compra de Produtos Ecológicos de Alunos de uma IES de Santa Catarina. ReAT, v.5, n.3, p.454-468, 2014. DOI: http://dx.doi.org/10.15210/REAT.V5I3.4761

THIENGKAMOL, N.. Development of model of environmental education and inspiration of public consciousness influencing to global warming alleviation. European Journal Publishing, v.25, n.4, p.506-514, 2011.

THONGPLEW, N.; SPAARGARENA, G.; KOPPEN, C. S. A. K.. Companies in search of the green consumer: sustainable consumption and production strategies of companies and intermediary organizations in Thailand. NJAS: Wageningen Journal of Life Sciences, v.83, p.12-21, 2017. DOI: https://doi.org/10.1016/j.njas.2017.10.004

TSENG, M. L.; CHIU, A. S. F.; LIANG, D.. Sustainable consumption and production in business decision-making models. Resources. Conservation and Recycling, v.128, p.118-121, 2018. DOI:

https://doi.org/10.1016/j.resconrec.2017.02.014

UNRUH, G.; ETTENSON, R.. Winning in the green frenzy. Harvard Business Review, v.88, n.11, p.110-116, 2010.

VICENTE-MOLINA, M. A.; FERNÁNDEZ-SÁINZ, A.; IZAGIRREOLAIZOLA, J.. Environmental knowledge and other variables affecting pro-environmental behaviour: comparison of university students from emerging and advanced countries.
Journal Cleaner Production, n.61, p.130-138, 2013. DOI: http://doi.org/10.1016/i.jclepro.2013.05.015

VILHENA, J. M.. Diretrizes para a Sustentabilidade das Edificações. Gestão e Tecnologia de Projetos, v.2, n.2, p.5978, 2007. DOI: http://doi.org/10.4237/gtp.v2i1.32

WANG, Y. F.. Modeling predictors of restaurant employees' green behavior: comparison of six attitude-behavior models. International Journal of Hospital Management, v.58, p.6681, 2016. DOI: https://doi.org/10.1016/j.ijhm.2016.07.007

WANG, Y. F.; CHEN, S. P.; LEE, Y. C.; TSAIA-SIMON, C. T.. Developing green management standards for restaurants: an application of green supply chain management.

International Journal of Hospital Management, v.34, p.263273, 2013. DOI: https://doi.org/10.1016/j.ijhm.2013.04.001

WEI, S. C.; LEVINE, J. H.; COGDILL, A. P.; ZHAO, Y.; ANANG, N. A. S.; ANDREWS, M. C.; SHARMA, P.; WANG, J.; WARGO, J. A.; PE'ER, D.; ALLISON, J. P.. Distinct Cellular Mechanisms Underlie Anti-Ctla-4 and Anti-Pd-1 Checkpoint Blockade. Cell, v.170, n.6, p.1120-1133, 2017. DOI: http://doi.org/10.1016/j.cell.2017.07.024

WELLS, V. K.; MANIKA, D.; GREGORY-SMITH, D.; TAHERI, B.; MCCOWLEN, C.. Heritage tourism, CSR and the role of employee environmental behavior. Tourism Management, v.48, p.399-413, 2015. DOI:

http://doi.org/10.1016/i.tourman.2014.12.015

YANG, D.; LU, Y.; ZHU, W.; SU, C.. Going green: how different advertising appeals impact green consumption behaviour. Journal of Business Research, v.68, n.12, p.2663-2675, 2015. DOI: https://doi.org/10.1016/j.jbusres.2015.04.004

ZAREI, A.; MALEKI, F.. From decision to run: the moderating role of green skepticism. Journal of Food Products Marketing, v.24, n.1, p.96-116, 2017.

ZIMBARDO, P. G.; BOYD, J. N.. Putting time in perspective: A valid, reliable individual-differences metric. Journal of Personality and Social Psychology, v.77, n.6, p.1271-1288, 1999. DOI: http://doi.org/10.1037/0022-3514.77.6.1271

ZSÓKA, Á.; SZERÉNYI, Z. M.; SZÉCHY, A.; KOCSIS, T.. Greening due to environmental education? Environmental knowledge, attitudes, consumer behavior and everyday proenvironmental activities of Hungarian high school and university students. Journal of Cleaner Production, v.48, p.126-138, 2013. DOI:

https://doi.org/10.1016/j.jclepro.2012.11.030

A CBPC - Companhia Brasileira de Produção Científica (CNPJ: 11.221.422/0001-03) detém os direitos materiais desta publicação. Os direitos referem-se à publicação do trabalho em qualquer parte do mundo incluindo os direitos às renovações, expansões e disseminacões da contribuicão, bem como outros direitos subsidiários. Todos os trabalhos publicados eletronicamente poderão posteriormente ser publicados em coletâneas impressas sob coordenação da Sustenere Publishing, da Companhia Brasileira de Produção Científica e seus parceiros autorizados. Os (as) autores (as) posteriormente ser publicados em coletâneas impressas sob coordenação da Sustenere Publishing, da Companhia Brasileira de Produção Cientifica e seus parc 